\title{
A review of the electrodeposition of metal matrix composite coatings by inclusion of particles in a metal layer: an established and diversifying technology
}

\section{F. C. Walsh*1,2 and C. Ponce de Leon ${ }^{1}$}

Following a brief overview of their history, which dates back to the 1920s with marked developments during the 1960s and 1970s, the principles of composite coatings, achieved by including particles dispersed in a bath into a growing electrodeposited metal layer, are considered. The principles and role of electroplating compared to other techniques for realising such coatings, are considered. A good quality particle dispersion (often aided by a suitable type and concentration of surfactants) appropriate choice of work-piece shape/geometry and controlled agitation in the bath are seen to be prerequisites for achieving uniform coatings having a well-dispersed particle content by electroplating. Examples are provided to illustrate the influence of bath composition and plating conditions on deposit properties. Engineering applications of included particle composite layers are illustrated by examples of hard ceramic, soft ceramic and polymer inclusion composite coatings from the recent literature. Current trends in the development of composite plated coatings are summarised and their diverse applications are seen to include the use of finely structured (especially nanostructured) and functionally active particles together with hybrid and more complex, e.g. hierarchical, structures for applications ranging from tribology to speciality electronics, magnetic and electrochemical energy conversion materials.

Keywords: Composite, Corrosion resistance, Inclusions, Surfactants, Tribology, Wear resistance

\section{Introduction}

Electrodeposition provides a versatile and convenient route to the realisation of controlled coatings of composites (i.e., materials having more than one phase) containing particles dispersed in a metal matrix compared to thermal and mechanical methods, such as powder metallurgy, metal spraying and nitriding or vacuum deposition, e.g. magnetron sputtering to prepare composite layers. ${ }^{1}$ The field of composite plating is also referred to as 'inclusion plating', the term inclusion also being traditionally used to refer to unwanted, contaminant particles, for instance, those insoluble inorganic materials such as metal oxides sedimenting in the bath and entrained in electrolyte flow which become co-deposited e.g. Lansdell and Farr. ${ }^{2}$ In this review, we will typically refer to $\mathrm{M}-\mathrm{X}$ coatings to mean a

${ }^{1}$ Electrochemical Engineering Laboratory, University of Southampton, Highfield, Southampton, SO17 1BJ, UK

${ }^{2}$ National Centre for Advanced Tribology at Southampton and Materials Engineering Research Group, University of Southampton, Highfield, Southampton, SO17 1BJ, UK

*Corresponding author, email: F.C.Walsh@soton.ac.uk metal matrix, $\mathrm{M}$ containing included solid particles, $\mathrm{X}$, e.g. Ni-SiC. It is important to realise, however, that electrodeposition (together with electrophoresis) is capable of coating, or occasionally electroforming, a diverse range of inclusion and matrix materials, including conducting polymer and ceramic matrices containing metal, polymer, ceramic and hybrid particles from aqueous electrolytes. ${ }^{3}$

Examples of composite plating can be traced back to as long ago as 1928 in a study of a $\mathrm{Cu}$-graphite coating for an automotive bearing in the USA. ${ }^{4}$ The subject saw major developments throughout the 1960s and 1970s, particularly in Europe ${ }^{5}$ due to interest in the diversity of possible coatings, the mechanism of particle co-deposition and the search for wear resistant coatings suitable for increasing demands in aerospace and automotive engineering. Much of the literature during this period is dedicated to hard ceramic particles in useful engineering metal matrices to realise $\mathrm{Ni}$ or $\mathrm{Co}$ layers containing carbides, nitrides or borides, such as $\mathrm{SiC}$ or WC. An important example is the development of $\mathrm{Ni}-\mathrm{SiC}$ composite coatings for the rotor tips of Wankel engines and the piston internal cylinder surfaces of reciprocating automotive engines, particularly by BMW, then later by 


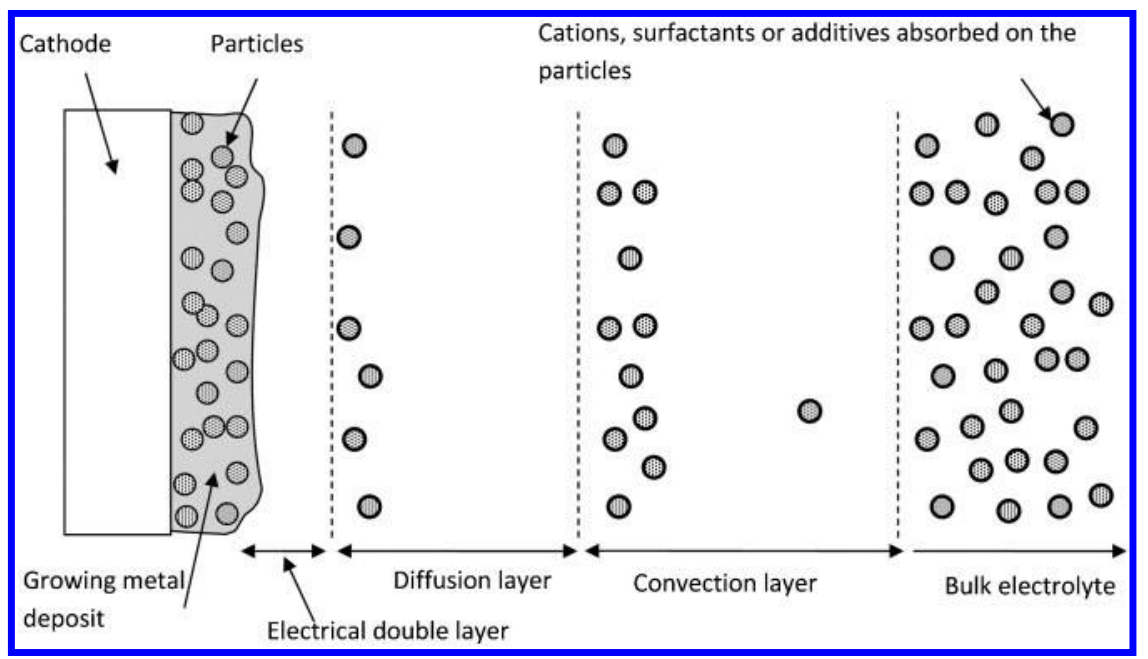

1 The processes involved in co-electrodeposition of insoluble particles into a growing metal matrix to form a composite metal coating

Porsche. In the 1970s, interest was shown in a broader range of nickel coatings containing $\mathrm{Al}_{2} \mathrm{O}_{3}$, graphite and polymers such as PTFE, e.g. for lubrication and corrosion protection. Since the 1970s, specialist applications have included semiconductor manufacture, wastewater treatment and fuel cell electrodes. The science and technology of composite plating has now matured into a recognisable sub-field of materials finishing and it is timely to provide a concise profile of this subject, with a focus on the last decade and a look at some of the more specialised coatings being internationally considered, such as metal layers containing layered and solid state lubricant materials, e.g. graphene, ${ }^{13} \mathrm{MoS}_{2}$ and $\mathrm{WS}_{2}{ }^{14}$ or nanostructured materials such as carbon nanotubes, ${ }^{15}$ titanium oxide tubes or fibres. ${ }^{16}$ For readers seeking more extensive, historical or specialised information, selected literature reviews, published between 1970 and the present, are noted in Table 1. A forthcoming review in this journal will consider the plating and anodising of nanostructured surfaces, including composite layers containing nanoparticles.

\section{The principles of composite plating The mechanism of composite plating and types of inclusions}

In this section, the mechanism and modelling of composite plating are briefly considered. While semicontinuous developments have been made since the 1960s, important leadership was offered throughout the 1970s, 1980s and beyond by several European university research groups, for example those under the guidance of Jannsen in Eindhoven ${ }^{9,10}$ and Celis in Leuven. ${ }^{4,11} \mathrm{~A}$ wide range of particles, typically from tens of nanometres to hundreds of microns in size and spheroidal, tubular, fibrous or lamellar in shape, can be incorporated into a metal deposit to form a composite coating. Fig. 1 summarises the major processes involved in the electroplating of particles into a growing metallic matrix. The incorporation of particles into metallic coatings can be achieved by a number of processes including convection of the particles towards the cathode surface, mechanical entrapment of particles

Table 1 Selected reviews of composite plating and their contents

\begin{tabular}{|c|c|c|c|}
\hline Authors & Year & Contents & Reference \\
\hline Roos, Celis, Fransaer, Buelens & 1990 & Includes mathematical models; considers early studies. & [4] \\
\hline Feldstein & 1990 & Electroless nickel composite layers. & [8] \\
\hline Helle, Walsh & 1997 & $\begin{array}{l}\text { Highlights the importance of surfactants to both } \\
\text { disperse particles in the bath and control electrophoresis. }\end{array}$ & [5] \\
\hline Musiani & 2000 & $\begin{array}{l}\text { Focuses on specialised electrochemical applications, } \\
\text { e.g. electrocatalysis, fabrication of photoactive } \\
\text { devices and energy storage. }\end{array}$ & {$[6]$} \\
\hline Kerr, Barker, Walsh & 2000 & General. Includes principles of the technology. & {$[7]$} \\
\hline Fransaer, Celis & 2001 & General. Review of mechanisms. & [92] \\
\hline Hovestad, Jannsen & 1995, 2005 & General. Mechanistic theories considered. & {$[9,10]$} \\
\hline Low, Wills, Walsh & 2006 & $\begin{array}{l}\text { Nanosized metal, polymer and ceramic particles } \\
\text { with examples of their properties. }\end{array}$ & {$[1]$} \\
\hline Cavallotti, Bestetti, Franz, Vicenzo & 2011 & $\begin{array}{l}\text { Pulsed electrodeposition and electrocrystallisation } \\
\text { at the nanoscale. }\end{array}$ & {$[12]$} \\
\hline Takadoum, Bercot & 2010 & $\begin{array}{l}\text { A book chapter on electrodeposition as a technique } \\
\text { to produce nanostructured coatings. Other techniques } \\
\text { are considered in the book. }\end{array}$ & {$[32]$} \\
\hline Low, Ponce de Leon, Walsh & $(2014)$ & $\begin{array}{l}\text { Nanostructured deposits by plating and anodising; } \\
\text { routes to achieving nanostructures using diverse } \\
\text { surfaces illustrated by examples. }\end{array}$ & {$[90]$} \\
\hline
\end{tabular}




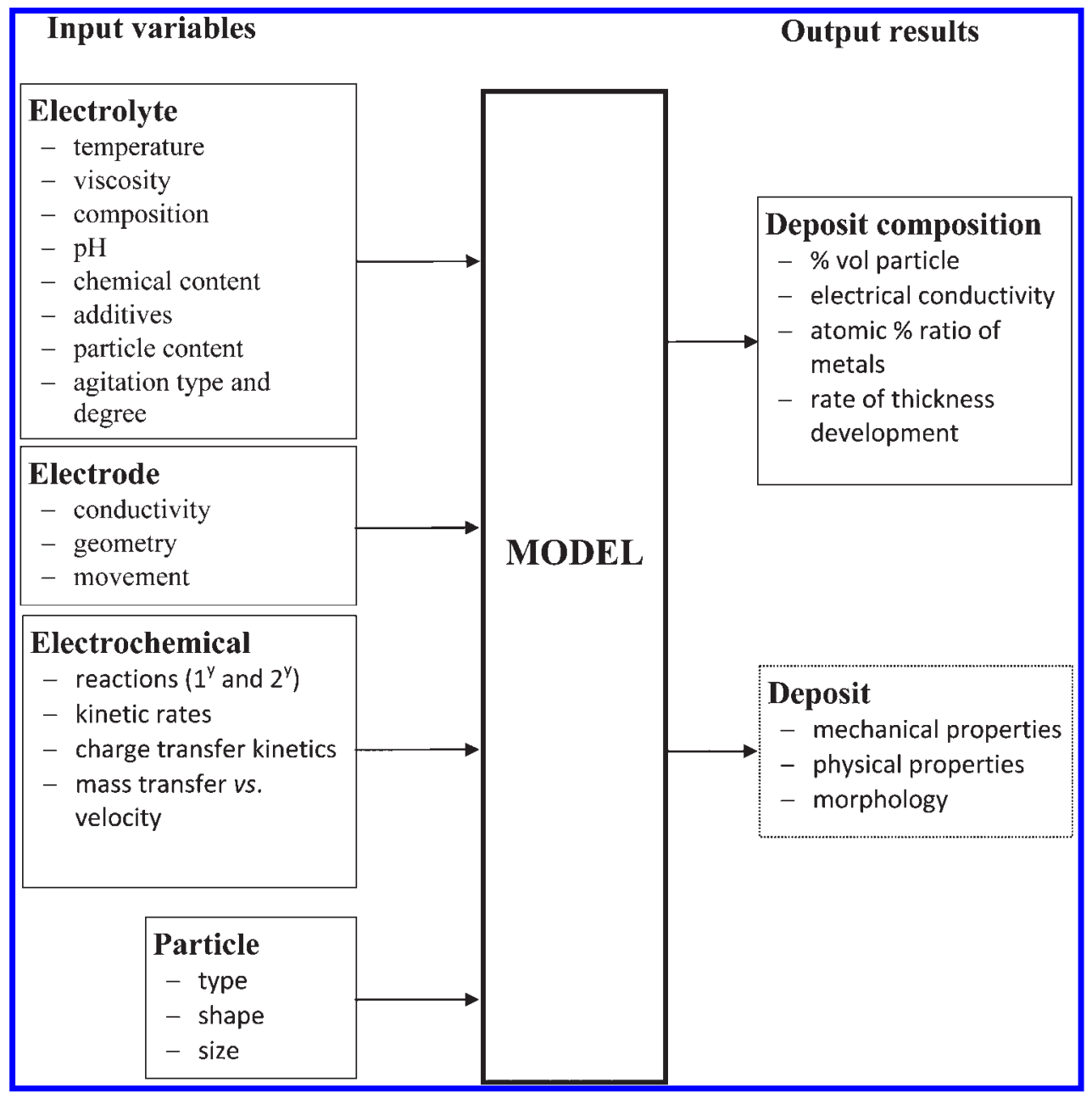

2 Input variables to a model of composite plating and the output results sought

into the growing metal matrix, and/or electrophoretic migration of particles to the growing metal deposit. The steps can be identified: (a) charged particle formation, e.g. due to ions and surfactants adsorbed on particle surfaces, (b) physical transport of particles through a convection layer, (c) mass transport of particles via a concentration boundary (diffusion) layer, (d) migration driven by the potential gradient across an electrical double layer and (e) physical embedding of particles into the growing metal deposit.

The successful co-deposition of particles into metal deposits is dependent on many process parameters, including characteristics of the particle (e.g. concentration, surface charge, type, shape, size), electrolyte composition (e.g. electrolyte concentration, additives, temperature, $\mathrm{pH}$, surfactant type and concentration), applied current density (e.g. direct current, pulsed current, pulse time, duty cycle, potentiostatic control), flow environment inside the electroplating tank (e.g. laminar, mixed, turbulent regimes), and shape/size of electroplating tank and electrode geometry (rotating disk electrode, rotating cylinder electrode, plate-in-tanks, parallel plate electrodes and many variations of electroplating tanks). The general factors affecting composite electroplated deposits are shown in Fig. 2, in the form of input variables to a model and the output results required.

Cross-sectional views of two composite metal coatings are shown in Fig. 3. The electrodeposited nickel coatings contain irregular but well-dispersed nanoparticles of solid silicon carbide $(\mathrm{SiC})$ or titanium oxide nanotubes. The dimensions in this figure indicate the diverse deposit thickness and particle size which can be involved. The particles can be agglomerated but, preferably, remain well-dispersed within the coatings. While the codeposition of metal and suspended particles is possible without surfactants, the quality of particle dispersion in the bath tends to be low and agitation plus work-piece geometry/ position become more critical. Moreover, adsorption of suitable surfactants on the particle surface serves to aid the achievement and maintenance of a good dispersion in the bath which facilitates a reliable and predictable dispersion of particles within the growing metal deposit. In electroless plating baths, particular care is needed to surfactant choice since particles, especially agglomerated ones, can act as nucleation centres for unwanted metal deposition or even 'bombing out' of metal in the bulk electrolyte, i.e., spontaneous metal plating in the bulk electrolyte.

\section{Mathematical modelling of composite plating}

Mathematical models are important in rationalising, simulating and predicting the relationships among bath composition, plating conditions and the quality of the coating (including the amount of included particles and their degree of dispersion).

The main driving forces for particle incorporation have been known since the early 1960s. In 1964, Williams and Martin ${ }^{17}$ suggested transport of particles 


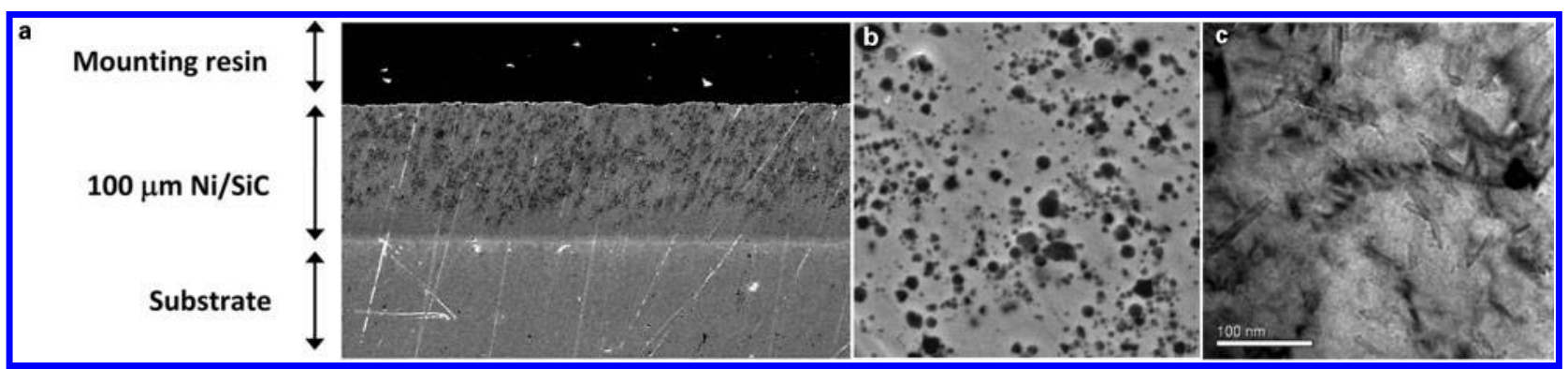

3 Examples of composite nickel-particle deposits; images of electrodeposited nickel coatings containing inclusions a and $b$ Cross-sectional images of composite nickel containing nanosized silicon carbide particles (darker). The coatings were electrodeposited from an electrolyte containing $1.5 \mathrm{~mol} \mathrm{dm}{ }^{-3}$ nickel sulfate, $5 \mathrm{~g} \mathrm{dm}^{-3}$ boric acid, $5 \mathrm{~mL} \mathrm{dm}^{-3} \mathrm{non}$ pitter wetter, $4 \mathrm{~mL} \mathrm{dm}{ }^{-3}$ hardener from Enthone UK and $1 \mathrm{~g} \mathrm{dm}^{-3}$ coumarin. Electrodeposition of nickel composites was carried out at $50 \mathrm{~mA} \mathrm{~cm}{ }^{-2}$ for $2 \mathrm{~h}$ at a temperature of $60^{\circ} \mathrm{C}$ and a rotation speed of $300 \mathrm{rpm}^{53}$ and $c$ Surface morphology of a nickel composite coating containing nanotubular titanates. Electrodeposition was carried out from a Watts nickel electrolyte containing $20 \mathrm{~g} \mathrm{dm}^{-3}$ of nanotubular titanates.at $50 \mathrm{~mA} \mathrm{~cm}^{-2}$ for $2 \mathrm{~h}$ at $60^{\circ} \mathrm{C}^{68}$

to the cathode by convection due to bath agitation. Bazzard and Boden ${ }^{18}$ proposed that particles collided with the cathode surface and required a certain residence time for inclusion. In 1967, Brandes and Goldthorpe ${ }^{19}$ considered that purely mechanical entrapment of particles was unlikely; rather, there must be a force of attraction, such as an electrostatic one. Guglielmi ${ }^{20}$ provided the first concerted model, which considered a two-step sequence:

(i) particles approach the cathode surface and become loosely adsorbed then

(ii) particles lose their ionic cloud and become strongly adsorbed.

The model involves electrophoresis of particles, charge transfer electrode kinetics (as approximated by the Tafel equation) and Langmuir adsorption of particles. ${ }^{20}$ Despite its shortcomings, which include a failure to consider mass transport of particles or ions of the plated metal matrix or particle type and size, this successful early model has been widely used to approximately describe many composite plated systems and is still cited in recent papers.

As realised by Bazzard and Boden $^{18}$ a certain residence time is needed for a particle to become adsorbed at the cathode surface and not all particles arriving at the cathode surface will be adsorbed. Degrez and Winand ${ }^{21}$ were aware that changes occur in the copper deposition mechanism due to electrocrystallisation changes and this provided another factor to be considered in composite plating, where growth of the metal matrix is critical for satisfactory particle inclusion. By considering this together with ion adsorption onto particle surfaces, bath agitation and convective-diffusion, Celis, Roos and Buelens ${ }^{22}$ proposed an improved, 5-step mechanism in 1987 which incorporated the essential features of Guglielmi's model into the final 2 steps:

(i) particles form an ionic cloud by ion adsorption,

(ii) particles are transported by convective-diffusion to the cathode,

(iii) the particles, complete with their ionic cloud, are adsorbed on the cathode surface,

(iv) the ionic cloud is shed, and

(v) the particles are included into the growing metal deposit.

A statistical approach was taken to the probability of a particle crossing the diffusion layer. This model is a significant improvement on that of Guglielmi but requires empirical factors specific to a system and found by experiment.

A useful summary of early mathematical models is provided in the Eindhoven Technical University $\mathrm{PhD}$ thesis of Hovestad ${ }^{23}$ and in the 1995 review by Hovestad and Janssen. ${ }^{10}$ In work in the Wilcox group at Loughborough University, Morana has provided a useful update to 2000 in a $2006 \mathrm{PhD}$ thesis ${ }^{24}$ while Fransaer and Celis have given a timely summary of developments in the field in 2001.

In 1997, Valdes ${ }^{25}$ proposed a 'perfect sink' model with the assumption of infinitely fast kinetics such that all particles arriving within a critical distance of the cathode surface were irreversibly captured. The model was developed with data from an RDE and considered both diffusion and convection. However, a major shortcoming is that the model predicted maximum codeposition of particles at the limiting current density, which disagrees with most experimental findings. Hwang and Hwang ${ }^{26}$ have built on Guglielmi's early model to suggest three current density ranges for reduction of adsorbed metal ions:

(i) at low current densities, only protons are reduced.

(ii) at intermediate current densities, proton reduction reaches a limiting condition and metal ions are reduced, and

(iii) at high current densities, the rate of proton and metal ion reduction reaches limiting values. This model appears never to have been validated by experimental data.

In 1992, Fransaer, Celis and Roos ${ }^{27}$ used an RCE study to propose a model based on a quantitative trajectory analysis of the forces acting on particles in the bath and approaching the cathode surface. Contributions to particle trajectory models have also been provided by Maurin and Lavanant. ${ }^{28}$ Also in 1992 , Vereecken, Shao and Searson ${ }^{29}$ showed that the rate of nanometre sized particles in a growing metal deposit could be described by a model which considers the relative contributions of gravitational forces and diffusion as a function of particle size. In 2002, Bercot et al. ${ }^{30}$ offered an improvement of Guglielmi's model and incorporated a polynomial correction to account for the effects of adsorption and flow. The problem of current distribution during composite plating and its modelling has been 
considered by workers in the USA ${ }^{80}$ Further studies would benefit from the use of controlled flow in, e.g., a rotating cylinder Hull $(\mathrm{RCH})$ cell. ${ }^{61}$

While the relationship between the quantity of particles in the metal deposit to the current density has been the focus of many experimental studies, relatively few workers have adopted a quantitative model to predict performance or at least to rationalise the results, despite the modelling work described above and an extensive review of inclusion co-deposition in 2001 which stresses the contradictory experimental data and lack of controlled hydrodynamics. ${ }^{93}$ To echo and extend the final sentence of this reference: A complete understanding of the composite electrodeposition process requires a synergy between theoretical models and thorough experimental work, always being mindful of the need to scale-up to practical systems.

Table 2 (after Low, Wills and Walsh ${ }^{1}$ ) attempts to summarise some of the major features of mathematical models aimed at describing composite plating over the thirty year period from 1972 to 2002. Despite the longterm refinement and testing of these models, it is clear that our current understanding of the mechanism of composite electroplating remains incomplete and unsatisfying. Models tend to be empirical rather than based on a close physical interpretation. Also, they (a) tend to have fitting parameters specific to a given bath and composite, (b) do not adequately consider particle size

Table 2 Examples of theoretical models used to describe the behaviour of metal electrodeposition containing included particles in the 30 year period 1972-2002. After Low, Wills and Walsh [1]

\begin{tabular}{|c|c|c|c|c|c|c|}
\hline \multirow[b]{2}{*}{ Model } & \multirow[b]{2}{*}{$\begin{array}{l}\text { Approach taken and assumptions } \\
\text { made }\end{array}$} & \multicolumn{5}{|c|}{ Deposit and process conditions } \\
\hline & & $\begin{array}{l}\text { Composite } \\
\text { layer }\end{array}$ & $\begin{array}{l}\text { Particle } \\
\text { size } / \mu \mathrm{m}\end{array}$ & $\begin{array}{l}\text { Current } \\
\text { density } \\
j / \mathrm{mA} \mathrm{cm} \mathrm{cm}^{-2}\end{array}$ & $\begin{array}{l}\text { Rotation } \\
\text { speed } \\
\omega / \text { rpm }\end{array}$ & Ref. \\
\hline Guglielmi, 1972 & $\begin{array}{l}\text { Describes both adsorption and } \\
\text { electrophoresis. The particles } \\
\text { are covered by adsorbed metal } \\
\text { ions. Particle characteristics and } \\
\text { electrolyte conditions are accounted } \\
\text { semi-empirically. The effect of flow } \\
\text { is not considered. }\end{array}$ & $\begin{array}{l}\mathrm{Ni}-\mathrm{TiO}_{2} \\
\mathrm{Ni}-\mathrm{SiC}\end{array}$ & $1-2$ & $20-100$ & $N G^{*}$ & {$[20]$} \\
\hline Celis, Roos \& Buelens, 1987 & $\begin{array}{l}\text { Uses probability to describe the } \\
\text { amount of particles that are likely } \\
\text { to be incorporated at a given } \\
\text { current density. Mass transport } \\
\text { of particles is proportional to the } \\
\text { mass transport of ions to the working } \\
\text { electrode. Volume ratio of particles } \\
\text { in the metal deposit will increase } \\
\text { under charge transfer control and } \\
\text { decrease under mass transport } \\
\text { control. }\end{array}$ & $\begin{array}{l}\mathrm{Cu}-\mathrm{Al}_{2} \mathrm{O}_{3} \\
\mathrm{Au}-\mathrm{Al}_{2} \mathrm{O}_{3}\end{array}$ & 0.05 & 0-90 & $400-600$ & {$[22]$} \\
\hline Fransaer, Celis \& Ross, 1992; & Uses trajectory to describe the & Cu-PS & 11 & $0-80$ & $0-700$ & {$[27]$} \\
\hline Maurin \& Lavanant, 1995. & $\begin{array}{l}\text { codeposition of non-Brownian } \\
\text { particles. Involves two steps: } \\
\text { reduction of metal ions (described } \\
\text { by Butler-Volmer expression) and } \\
\text { codeposition of particle (described } \\
\text { by a trajectory expression). }\end{array}$ & $\mathrm{Ni}-\mathrm{SiC}$ & $0 \cdot 01-10$ & 0-200 & 0-2000 & [28] \\
\hline Hwang \& Hwang, 1993 & $\begin{array}{l}\text { An improvement of Guglielmi's } \\
\text { model which uses three modes of } \\
\text { current density (low, intermediate, } \\
\text { high) to distinguish the reduction of } \\
\text { adsorbed ion on particles. Involves } \\
\text { three steps: forced convective of } \\
\text { particles to surface, loose adsorption } \\
\text { on the surface and irreversible i } \\
\text { ncorporation of particles by reduction } \\
\text { of adsorbed ions. }\end{array}$ & Co-SiC & 3 & $1-60$ & 400 & {$[26]$} \\
\hline $\begin{array}{l}\text { Vereecken, Shao, \& Searson, } \\
2000\end{array}$ & $\begin{array}{l}\text { The transport of particles to the } \\
\text { surface is controlled by convective- } \\
\text { diffusion. The influence of particle } \\
\text { gravitational force and hydrodynamics } \\
\text { is accounted for at various current } \\
\text { densities. Valid only when the particle } \\
\text { size is smaller than the diffusion layer } \\
\text { thickness. }\end{array}$ & $\mathrm{Ni}-\mathrm{Al}_{2} \mathrm{O}_{3}$ & $0 \cdot 3$ & $5-40$ & $500-2000$ & {$[29]$} \\
\hline $\begin{array}{l}\text { Bercot, Pena-Munoz \& Pagetti, } \\
2002\end{array}$ & $\begin{array}{l}\text { An improvement of Guglielmi's model, } \\
\text { which incorporates a 3rd order } \\
\text { polynomial correction to account for } \\
\text { the effects of adsorption and flow. }\end{array}$ & Ni-PTFE & 0.5 & $10-70$ & $400-1000$ & {$[30]$} \\
\hline
\end{tabular}

*NG: not given; PS: polystyrene. 


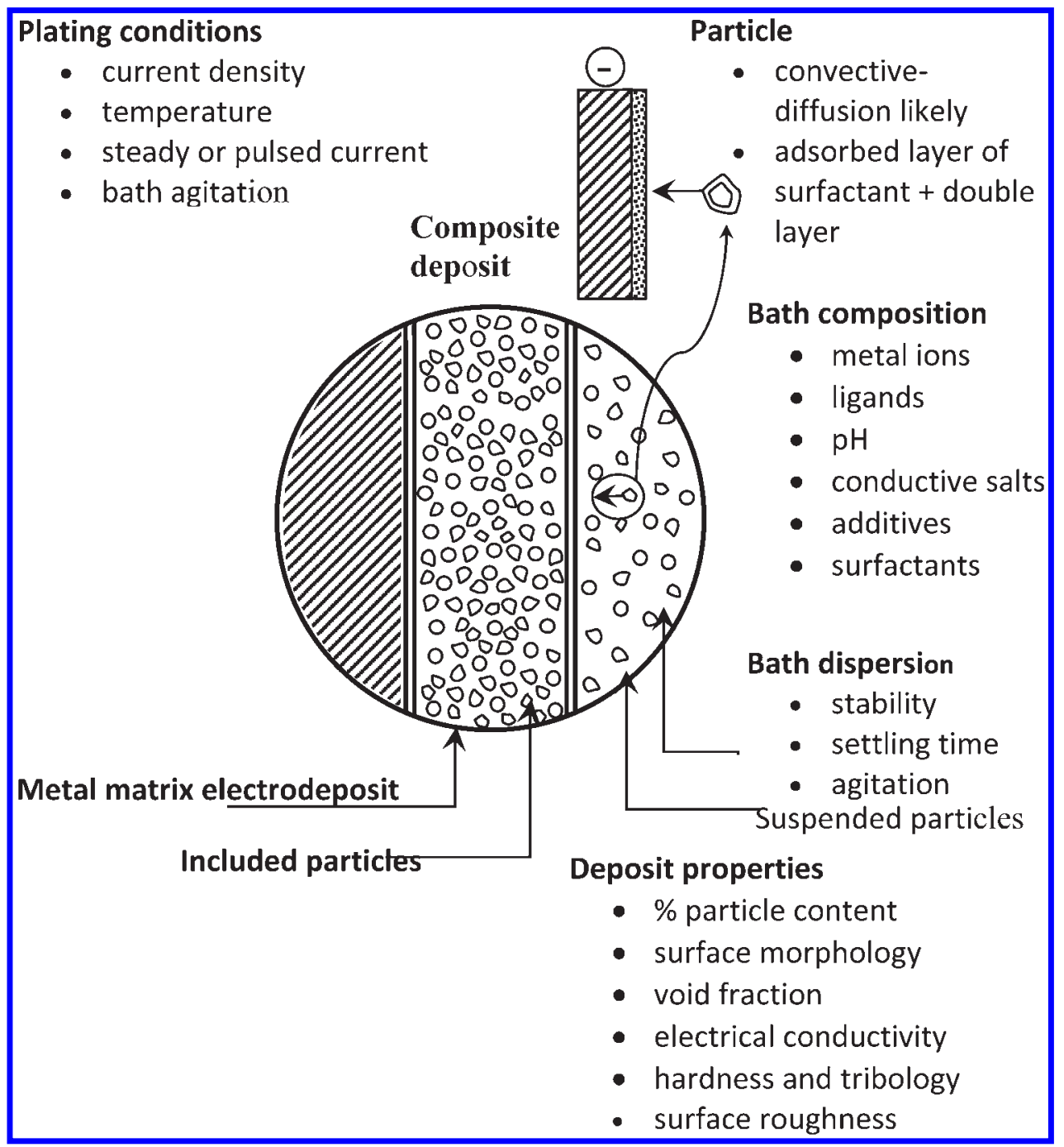

4 Factors influencing the quality of composite plating, grouped according to the bath composition, plating conditions and electrode/bath geometry

or shape, (c) ignore particle-metal matrix interactions, (d) do not adequately account for deposit development and metal growth with time, e) represent data over narrow ranges of experimental variables and (f) fail to consider the quality of the particle dispersion and its colloid chemistry in the plating bath. Any future model must overcome these limitations and adopt a userfriendly, multi-physics approach using accessible software to facilitate predictions and simulations.

\section{The practice of composite plating}

\section{General considerations}

Many factors influence the quality of composite plating. For convenience, these can be grouped (Fig. 4) according to the bath composition, plating conditions and electrode/bath geometry. The selected examples in Table $3^{31-37}$ illustrate the diversity of recent baths used for the plating of various composite coatings. The majority of baths are chosen due to their well established position in plating the matrix metal. Baths such as Watts nickel solutions are also tolerant to many surfactants and particle suspensions.

The inclusion of particles into metal deposits is dependent on many process parameters, including particle characteristics (particle concentration, surface charge, type, shape, size); electrolyte composition (electrolyte concentration, additives, temperature, $\mathrm{pH}$, surfactant type and concentration); current density (direct current, pulsed current, pulse time, duty cycle, potentiostatic control) and hydrodynamics (laminar, mixed, turbulent regimes) of electrochemical cells together with electrode geometry, as discussed below. A clear picture of the exact effect of the experimental parameters is, however, difficult to obtain. The majority of recent investigations have suggested that three global factors can be identified as influencing the co-deposition processes, namely, the particle type and concentration, the applied current density and electrode geometry/ movement or bath agitation.

A number of general comments may be made on composite plating practice in the literature:

1. The coatings usually consist of two distinct phases, namely, a discontinuous particle phase distributed within a continuous plated metal matrix phase.

2. While electroplating is a common and versatile coating technique, other means of achieving composite layers include mechanical liquid-solid roll-bonding, ${ }^{38}$ magnetron sputtering ${ }^{46}$ or electroless deposition, e.g. Ni-P-diamond, ${ }^{39} \mathrm{Ni}-\mathrm{P}$-kaolin, ${ }^{40}$ $\mathrm{Ni}-\mathrm{P}-\mathrm{TiO}_{2},{ }^{41} \mathrm{Cu}$-cubic $\mathrm{BN}^{42}$ and $\mathrm{Ni}-\mathrm{Al}_{2} \mathrm{O}_{3}-\mathrm{Y}_{2} \mathrm{O}_{3}$ carbon nanotubes. ${ }^{43}$ 


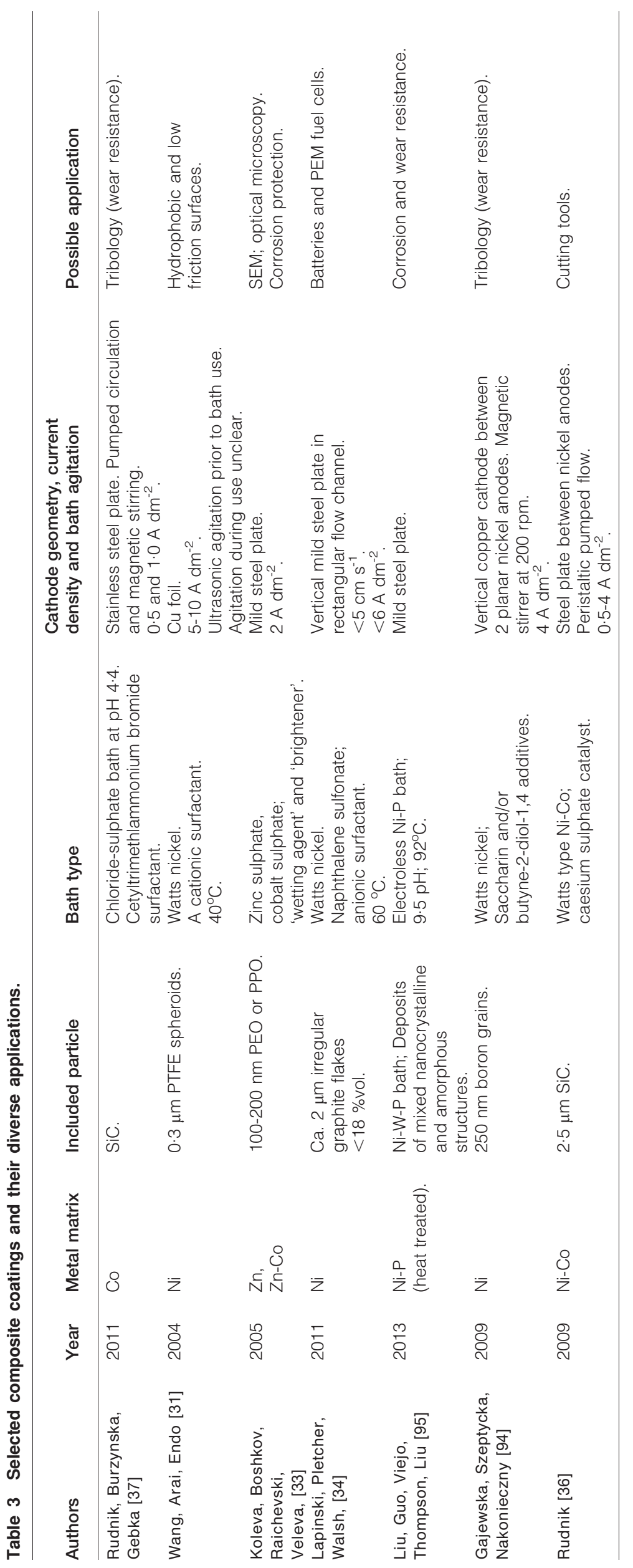




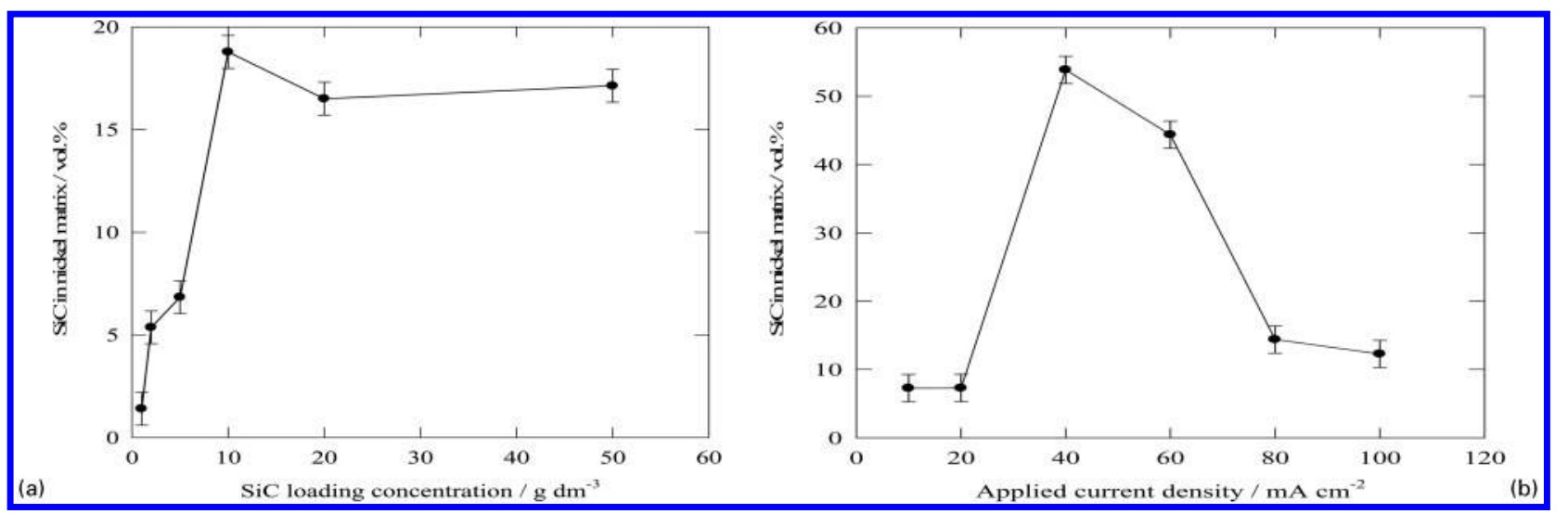

5 The effect of $a$ bath particle loading and $b$ current density on the nanosized particle content of Ni-SiC deposits. For $a$, the electrolyte contained $1 \mathrm{~g} \mathrm{dm}^{-3}$ coumarin and $10 \mathrm{~g} \mathrm{dm}^{-3}$ dispersed silicon carbide nanoparticles. For $b$, the electrolyte contained $2 \mathrm{~g} \mathrm{dm}^{-3}$ coumarin and silicon carbide nanoparticles in the solution. Electrodeposition of coatings was carried out at a vertical plate stainless steel cathode at $50 \mathrm{~mA} \mathrm{~cm}{ }^{-2}$ and $60^{\circ} \mathrm{C}$ for $2 \mathrm{~h}$ with continuous bath agitation with a $300 \mathrm{rpm}$ magnetic stirrer. After Low, Bello and Walsh ${ }^{53}$

3. Amongst the many metal matrices used, copper and nickel deposits have featured most strongly, together with constructional (and stainless) steels and brass but there are examples of metal matrices such as $\mathrm{Co}^{44}$ (especially for higher temperature, oxidation resistant applications), polymers such as ABS and polyamides ${ }^{45}$ and ceramics such as $\mathrm{TiO}_{2}$ in magnetron sputtered coatings. ${ }^{46}$

4. An extremely wide variety of particles (most commonly spheroidal or irregular in shape), ranging from $<2 \mathrm{~nm}$ to $>100 \mu \mathrm{m}$ in diameter, has been successfully incorporated into metal electrodeposits. Particle inclusion materials include ceramics such as alumina, $\left(\mathrm{Al}_{2} \mathrm{O}_{3}\right){ }^{26,28,43,44}$ kaolin $\left(\mathrm{Al}_{2} \mathrm{O}_{3} \cdot 2 \mathrm{SiO}_{2} \cdot 2 \mathrm{H}_{2} \mathrm{O}\right),{ }^{40}$ diamond $^{39}$ or graphite (C) ${ }^{34}$ silicon carbide $(\mathrm{SiC}),{ }^{37,47}$ silicon dioxide $\left(\mathrm{SiO}_{2}\right),{ }^{48}$ zirconium dioxide $\left(\mathrm{ZrO}_{2}\right),{ }^{49}$ titanium dioxide $\left(\mathrm{TiO}_{2}\right),{ }^{41}$ yttrium oxide $\left\{\mathrm{Y}_{2} \mathrm{O}_{3}\right),{ }^{43}$ silicon nitride $\left(\mathrm{Si}_{3} \mathrm{~N}_{4}\right),{ }^{39,47}$ chromium carbide $\left(\mathrm{Cr}_{3} \mathrm{C}_{2}\right){ }^{50}$ tungsten carbide (WC) ${ }^{51}$ and boron nitride $(\mathrm{BN}){ }^{42}$ polymers including polystyrene (PS) ${ }^{53}$ and polyaniline (PAni) ${ }^{49}$ and metals such as silver $(\mathrm{Ag})^{37}$ and chromium $(\mathrm{Cr}){ }^{50}$ Alumina in copper $\left(\mathrm{Cu}-\mathrm{Al}_{2} \mathrm{O}_{3}\right)$ and silicon carbide particles in nickel (Ni-SiC) composite layers have been the traditional subject of most investigations, including model studies.

5. While the majority of studies involve a single metal matrix, exceptions include speciality alloys such as $\mathrm{Co}-\mathrm{W}-\mathrm{Al}_{2} \mathrm{O}_{3}{ }^{44}$ and CoNiMnP-BaFe ${ }_{12} \mathrm{O}_{19} \cdot{ }^{35}$

6. Both complex e.g. ternary $\mathrm{Al}-\mathrm{Cu}-\mathrm{Fe}$ quasi-crystal particles in $\mathrm{Ni}^{52}$ and hybrid particle, e.g. titanate nanotubes and polypyrrole in $\mathrm{Ni}^{32}$ and $\mathrm{Al}_{2} \mathrm{O}_{3}-$ $\mathrm{Y}_{2} \mathrm{O}_{3}$-carbon nanotube ${ }^{43}$ inclusions in $\mathrm{Ni}$ have been considered in special cases.

\section{The effects of bath composition}

Electrolyte composition is known to be a significant factor affecting the co-deposition process. The concentrations and type of metal salt, in different electrolyte, additives and surfactants are all important as is the $\mathrm{pH}$ together with the presence of complexants and $\mathrm{pH}$ buffers. There have been very few systematic studies of the effects of bath composition on composite plating, most studies preferring to use a well established bath (and temperature) for the matrix metal. An obvious variable is the choice of particle type, shape and size distribution. While there are few relevant studies, an increasing number of workers have shown that use of nanosized particles rather than ones tens of microns in size have given rise to improved deposit properties. For example, recent studies of $\mathrm{Ni}-\mathrm{SiC}$ have shown the improved microhardness and microstructure of composite deposits using $20 \mathrm{~nm}$ rather than $1 \mu \mathrm{m}$ particles. ${ }^{52,53}$ It is common to find an increase in particle content with the bath loading of particles until a saturation point is reached, e.g. Fig. 5a. (Low et al. ${ }^{53}$ ). A few studies have avoided the complexity of surfactants and elected to use an additive-free bath, e.g. Gyftou et al. ${ }^{54}$

\section{Importance of plating conditions}

Current density is a major parameter governing the concentration of particles included in the metal matrix. Generally, an optimum range exists well within the normal limits for the optimum current density range for the electrodeposited metal matrix and this guides the choice of current density for composite plating. Many studies have found that modest increases in current density lead to a higher particle incorporation in the deposit but behaviour can be complex. In the case of nanosized $\mathrm{SiC}$ particles in a nickel deposit from a specific Watts Ni bath containing fixed additives and at under constant bath agitation from a magnetic stirrer, a clear maximum is seen in the particle content of the deposits as the current density range is traversed (Fig. 5b).

Several recent studies have examined the importance of pulsed control of current rather than the traditional use of steady direct current. For example, in a study of $\mathrm{Ni}-\mathrm{SiC}$ deposition, ${ }^{54}$ pulsed current was found to offer more uniform particle distributions and improved physical properties.

\section{Electrode geometry and bath agitation}

Fig. 6 attempts to summarise some of the electrode geometries and types of bath agitation used in composite plating. For laboratory investigations, magnetic stirring, rotating disk or cylinder electrodes (RDEs or RCEs) and parallel plate channel flow are commonly employed while in industrial processes, popular methods used in open tanks include the overhead blade stirrer, the 

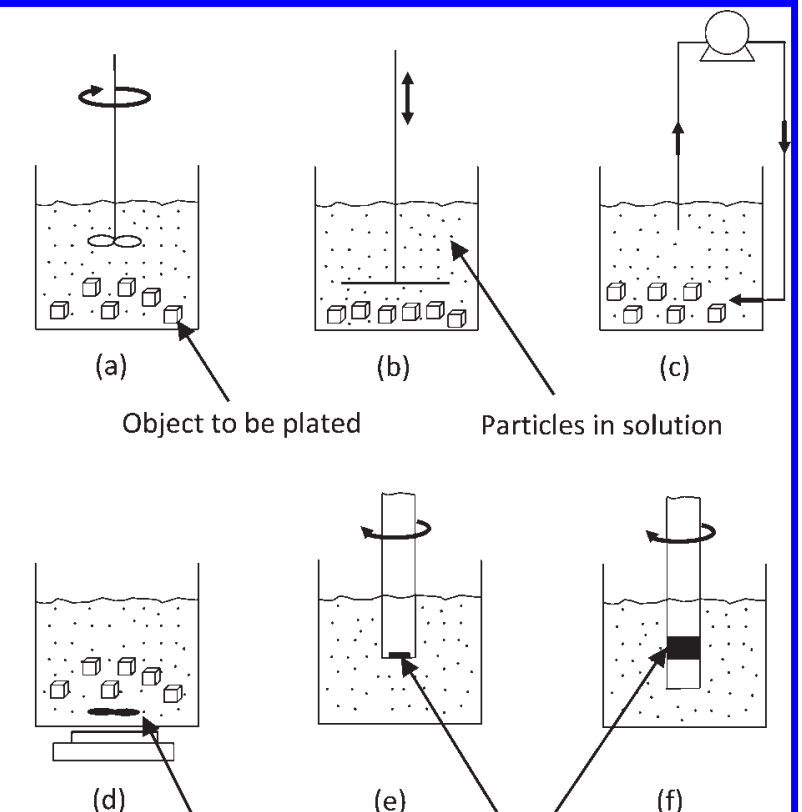

(d) Magnetic stirrer

(e)

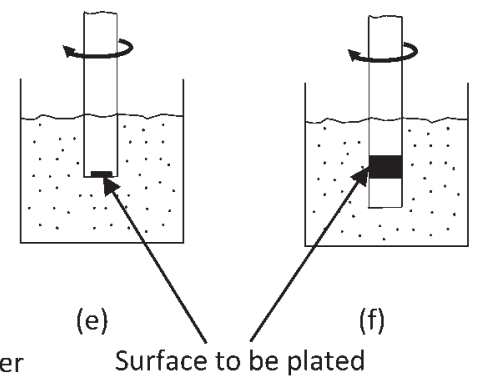

(g)

Surface to be plated

For industrial applications, popular agitation methods used in open tanks include: $a$ an overhead blade stirrer, $b$ a reciprocating plate plunger, and $c$ pumped electrolyte. For laboratory investigations, methods include: $d$ magnetic stirrer, $e$ a rotating disc electrode, $f$ rotating cylinder electrodes, and $g$ flow between parallel plates. The black area is the cathode surface where electrodeposition occurs and the white areas are insulating surfaces. Modified from a version by Low, Wills and Walsh ${ }^{1}$

6 Examples of electrode geometry and types of bath agitation used in composite plating

reciprocating plate plunger or a pumped recycle loop of the electrolyte. The rotating disk electrode, rotating cylinder electrode and parallel plates in a rectangular channel flow provide controllable hydrodynamics for quantitative characterisation of electrolytes containing particle suspensions. Three different flow regimes can be distinguished: laminar, transitional (laminar to turbulent) and turbulent but it is important to realise that, at commonly encountered rotation speeds, the smooth RDE remains in laminar flow while, even at relatively low rotation speeds, the RCE generates severe turbulence and mixing. ${ }^{55,56}$ For micron sized particles, there is generally no significant influence of electrolyte flow on particle content in the laminar region; in the transition regime, the particle content increases at higher flow rates; and in the turbulent regime, the particle content tends to decrease as the rate of flow increases. ${ }^{10}$

Despite the known importance of convective-diffusion, hence relative cathode-bath movement, many academic studies of composite plating have been carried out under poorly characterised or badly controlled hydrodynamic conditions. Few workers would deny the convenience and availability but the poorly defined, difficult to replicate, complex and vortex-prone flow induced by a magnetic stirrer follower in a parallel plate geometry is rarely appreciated. In a few cases, however, rotating disc electrode (RDE), ${ }^{24}$ rotating cylinder electrode $(\mathrm{RCE})^{23,55,56}$ have been used to offer well-defined laminar or turbulent flow together with predictable mass transport to smooth electrode surfaces. A few workers have preferred flat electrodes in rectangular channel flow for convenience and to simulate industrial practice, as in the case of recent studies on electrically conductive nickelgraphite. ${ }^{34}$ Occasionally, more specialised controlled flow environments are experienced, such as deposition of $\mathrm{Cu}-$ $\mathrm{Al}_{2} \mathrm{O}_{3}$ layers under impinging jet electrolyte conditions ${ }^{57-59}$ or pumped flow through a vertical, rectangular channel. ${ }^{60}$ Thus, common cathode geometries are the RDE, ${ }^{11,64}$ $\mathrm{RCE}^{55,56,63}$ and vertical plate electrodes. ${ }^{34}$ Methods of bath agitation have included magnetic stirring, e.g. Low et al. ${ }^{53}$ or overhead motor driven impeller blade stirrers, e.g. Muralidhara et al. $^{67}$ Ultrasonics has occasionally been considered. ${ }^{65}$ For rapid laboratory studies involving frequent changes in cathode work-piece material or surface finish, the authors have found a simple, benchtop RCE cell to be particularly convenient ${ }^{56,63}$ (Fig. 7).

This design, which typically involves a $5 \mathrm{~cm}$ length, $1.8 \mathrm{~cm}$ diameter tube, typically rotating at $c a .200 \mathrm{rpm}$ (ca. $20 \mathrm{~cm} \mathrm{~s}^{-1}$ peripheral cylinder velocity), provides good, turbulent, 3-dimensional mixing (to assist particle suspension and predictable turbulent flow as well as ease of storing plated samples prior to analysis (e.g. in desiccated screw-top sample tubes). The cell was used by one of the authors in Ni-PTFE and Ni-diamond plating in the AKZO corporate research laboratory of Helle in $1974^{63}$ and has since found use in our laboratories; switching to a bottom, circular disc anode and a longer RCE facilitates a rotating cylinder Hull $(\mathrm{RCH})$ cell geometry. ${ }^{56,61,62}$

The effect of flow can be complex and is often underestimated, despite its overriding importance to particle suspension in the bath and composite deposit quality. Many studies have found that, for a particular bath composition, electrode geometry and type of flow, there is a maximum in the particle content of the deposit with flow magnitude. Examples include:

(i) early use of RDEs includes $\mathrm{Cu}-\mathrm{Al}_{2} \mathrm{O}_{3}$ deposition by Celis et al.; ${ }^{11,64}$ some workers have used an $\mathrm{RDE}$ at a fixed rotation speed, e.g. $200 \mathrm{rpm}$ in Gyftou et al., 54

(ii) the RCE has occasionally been used and provides well agitated, turbulent flow, ${ }^{54,56}$ including demountable pipe section substrates at a fixed rotation speed, ${ }^{63}$ and

(iii) vertical plate electrodes and magnetic stirring of the bath remains a convenient and frequently used option, e.g. $37,48,50,52$

\section{Examples of traditional and future applications}

Selected composite coatings have been provided in Table 3. The diversity of coatings and industrial sectors is striking. In addition to the development of alloy metal matrices, speciality applications such as magnetic, electronic, optical and battery materials are broadening 


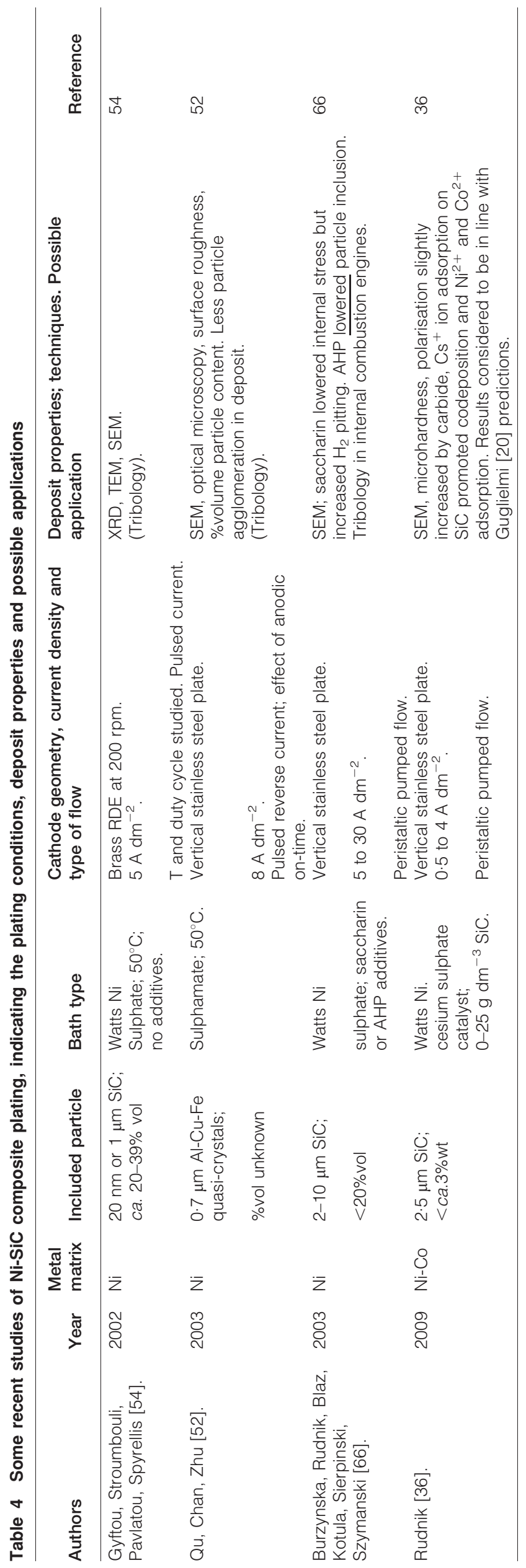

uses and adding to traditional markets such as tribological coatings and cutting tools.

\section{Metal-hard ceramic particles}

The use of ceramic particles in a metal matrix has long been used as a means of achieving tough, dispersionhardened coatings For example, a major impact of composite plated coatings has traditionally been in automotive engines for wear resistance and improved lubrication, where Ni-SiC and Ni-PTFE are both accepted coating options, e.g. in high performance internal combustion cylinder liners such as those used in prestige road cars or competitive automotive sports cars and motorcycles. A more specialist use has been in wear resistant tool facings, where competition exists from thin vacuum deposited layers, such as Co-WC and Ni-TiN ones. Surviliene and co-workers at Vilnius University have examined the effect of $\mathrm{SiC}$ on the corrosion behaviour of $10 \mu \mathrm{m}$ thick chromium coatings electroplated from a hexavalent bath containing $10 \mathrm{~g} \mathrm{dm}^{-3} \mathrm{SiC}$, making extensive use of electrochemical impedance spectroscopy at the corrosion potential in $0 \cdot 01 \mathrm{M} \mathrm{H}_{2} \mathrm{SO}_{4}+0.5 \mathrm{M} \mathrm{Na}_{2} \mathrm{SO}_{4} \cdot{ }^{51}$ As shown in Fig. 8, the composite coatings showed a much lower corrosion rate than a chromium plated layer, as evidenced by their increased charge transfer impedance (i.e., larger semicircles) especially in the case of hybrid Ni-WC-SiC composite coatings deposited from baths containing higher particle concentrations.

$\mathrm{Ni}-\mathrm{SiC}$ is the most commonly studied composite coating achieved by electrodeposition. Recent examples are given in Table 4.

\section{Metal-polymer particles}

Applications for metal-polymer particles include selflubrication, corrosion protection or speciality uses, such as electrode structures in modern batteries and proton exchange membrane (PEM) fuel cells. In the case of chemically inert but hydrophobic particles, such as PTFE, the choice of particle size and surfactant type and concentration are critical in achieving stable bath suspensions and high, controlled particle loadings in the metal deposit. This is sometimes rendered more difficult by the source of PTFE suspensions, which are often based on anionic surfactants and alcoholic/aqueous liquids which are not specifically designed for compatibility with plating baths. Earlier studies have been reviewed by Helle and Walsh ${ }^{5}$ and Kerr et $a l^{7}$ and progress through the 1970s and 1980s owes much to European work by the Celis group at the University of Leuven,, 22 Janssen and colleagues at Eindhoven University ${ }^{9,10}$ and Helle and coworkers at AKZO CRT in the Netherlands. ${ }^{5,74,75}$

Polymer inclusions have also been used to improve the degree of corrosion protection offered by sacrificial zinc deposits to mild steel substrates undergoing weathering under atmospheric conditions. Common examples of such particles include polystyrene, polyester, polyurethane and polyaniline. An example is provided by the electrodeposition of Zn-polyolefin oxides and $\mathrm{Zn}-\mathrm{Co}-$ polyolefin oxides, where linear potential sweep polarisation of the composite deposit was used to show an improvement in corrosion resistance compared to metal layers without polymer in $5 \mathrm{wt} . \% \mathrm{NaCl}$ at $25^{\circ} \mathrm{C}^{33}$

Although this review is focused on electrodeposited composites, development in the related electrolytic treatment of anodising deserves mention. Koleva et al. have successfully incorporated polyaniline into an 


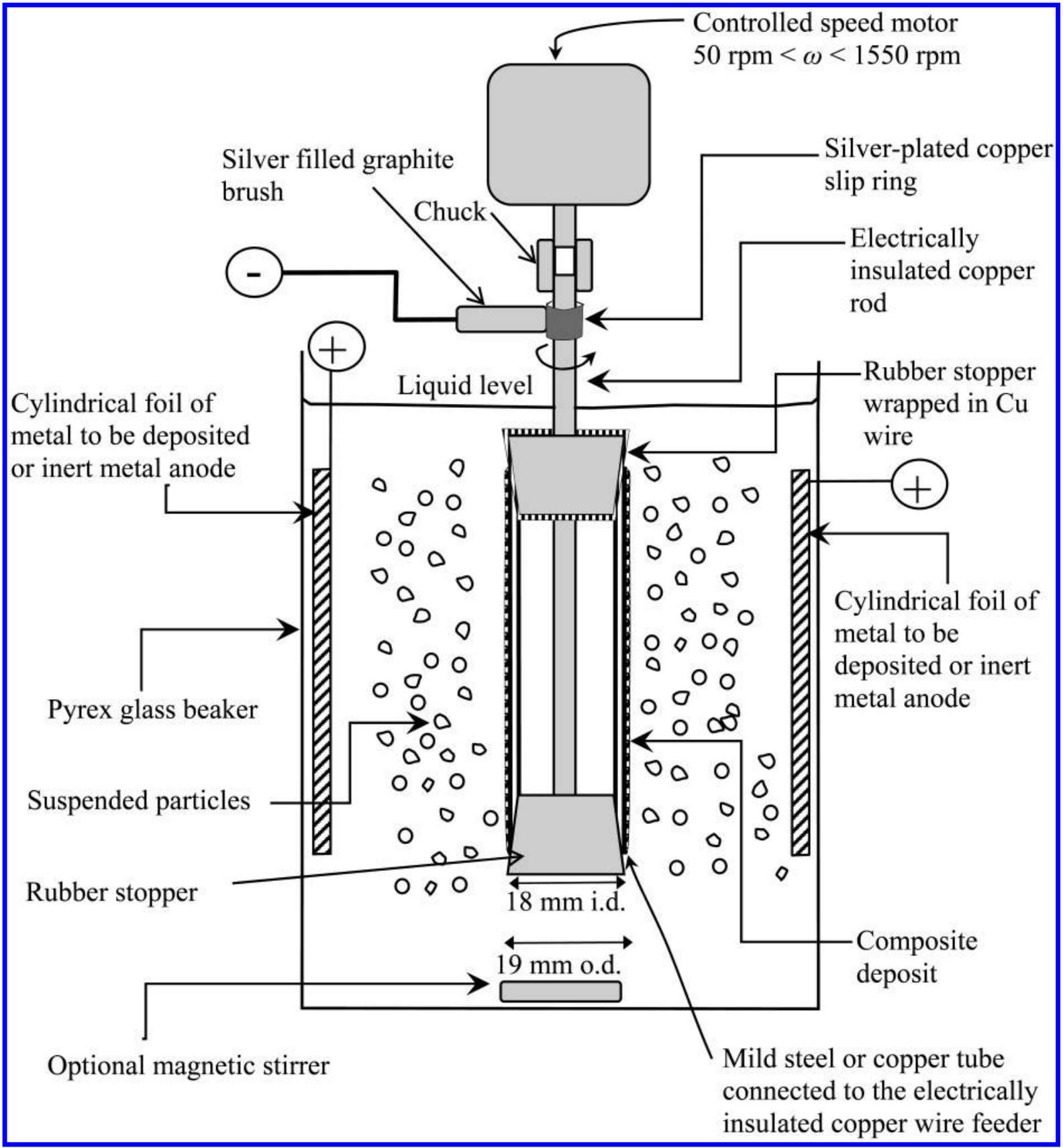

7 A practical cell for composite plating using a removable, thin-walled RCE cathode. After Walsh and Helle, $1974^{63}$

anodised array on a titanium foil surface. ${ }^{72}$ In the first stage, an anodised array was formed by anodising titanium in $2.0 \mathrm{M} \mathrm{H}_{3} \mathrm{PO}_{4}$ and $0.2 \mathrm{M} \mathrm{NH}_{4} \mathrm{~F}$ at $20 \mathrm{~V}$ at $20^{\circ} \mathrm{C}$. The anodic film was calcined to anatase by heat treatment at $500^{\circ} \mathrm{C}$ for $3 \mathrm{~h}$. In the second stage, aniline was adsorbed into the nanopores by anodically activating in a solution containing $0 \cdot 1 \mathrm{M} \mathrm{HNO}_{3}$ and $0.2 \mathrm{M}$ aniline at $20^{\circ} \mathrm{C}$ and $15 \mathrm{~mA} \mathrm{~cm}{ }^{-2}$ for $60 \mathrm{~s}$, followed by electropolymerisation by cyclic voltammetry in $0.5 \mathrm{M}$ $\mathrm{HClO}_{4}$ containing $0 \cdot 1 \mathrm{M}$ aniline. Subsequent cyclic voltammetry of the composite film in $0 \cdot 1 \mathrm{M} \mathrm{HNO}_{3}$ and $0.2 \mathrm{M}$ aniline at $20^{\circ} \mathrm{C}$ at a potential sweep rate of $20 \mathrm{mV} \mathrm{s}^{-1}$ showed reversible redox behaviour typical of the emeraldine form of polyaniline on cycling.

\section{Metal-softer ceramic particles}

Soft ceramic particles have been used for improved electrical contact as well as enhanced tribological surfaces. In the case of a noble metal coating matrix, such as nickel composites on mild steel, galvanically aggravated localised corrosion of the substrate at pore sites is a particular problem. Workers at Southampton University have recently examined a range of nickel coating, including a Ni-graphite composite. Although nickel deposition is carried out well below the mass transport limited rate (as estimated from voltammetric data), the mass transport regime was, however, the critical parameter in obtaining the desired dispersion of graphite particles within the electroplated $\mathrm{Ni}$ layer. Figs. 9a), b) and c) show typical SEM images for Ni/ graphite deposits in three cells, a stirred beaker, a Hull cell and upward flow in a rectangular channel. While the electrolyte conditions are identical, the current densities are not; the decision was taken to make the comparison at current densities where uniform and reflective $\mathrm{Ni}$ deposits were plated in the absence of carbon particles in 


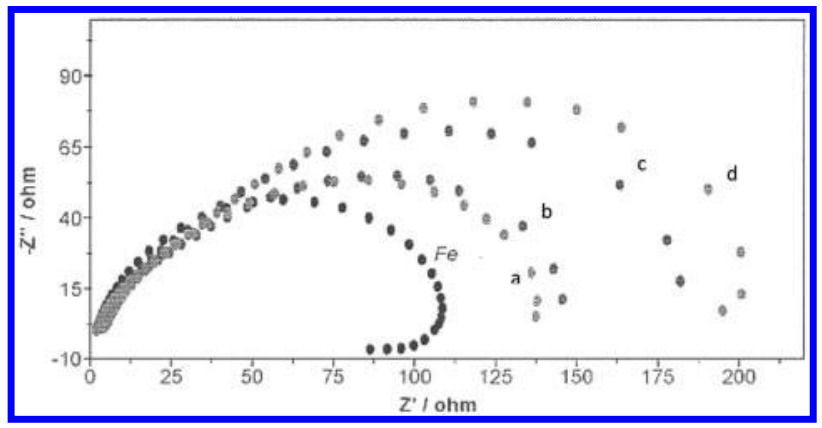

8 EIS spectra of a $10 \mu \mathrm{m}$ Cr-WC-SiC composite coating in salt sprayed $0.01 \mathrm{M} \mathrm{H}_{2} \mathrm{SO}_{4}+0.5 \mathrm{M} \mathrm{Na} \mathrm{NO}_{4}$, at the corrosion potential after $72 \mathrm{~h}$ exposure, showing the improved corrosion resistance of the composite coating The plot shows data for: $F$ e the mild steel substrate, $b$ a plated chromium coating; and composite coatings of Cr-WC-SiC deposited at $40 \mathrm{~A} \mathrm{dm}^{-2}$ from baths containing $b$ $20 \mathrm{~g} \mathrm{dm}^{-3}, c 60 \mathrm{~g} \mathrm{dm}^{-3}$ and $d 100 \mathrm{~g} \mathrm{dm}^{-3} \mathrm{WC}$ and $\mathrm{SiC}$ particles. After Surviliene et al..$^{51}$

the electrolyte. Hence, in the flow cell with a far superior mass transport regime, it was possible to obtain high quality deposits with a current density of $100 \mathrm{~mA} \mathrm{~cm}^{-2}$ whereas, in the Hull cell and beaker cells, poor deposits are plated at this current density and the current density needs to be in the range $10-20 \mathrm{~mA} \mathrm{~cm}^{-2}$ to obtain reasonable deposits. The efficient mass transport regime both increases the rate of transport of $\mathrm{Ni}^{2+}$ and graphite particles to the surface as well as controlling the distribution of graphite particles in the electrolyte, and also removes any hydrogen bubbles formed from the secondary reaction. Fig. 9(a) shows the SEM image from the Hull cell experiment and the graphite particles are closely packed over the surface. With the deposit formed in the beaker cell with better stirring than the Hull cell, Fig. 9(b), the graphite particles are more spaced but there is still agglomeration of particles into clumps. In the flow cell, the graphite particles are now well spaced and the graphite is largely present as individual particles, see Fig. 9(c).

The corrosion behaviour of these Ni-graphite deposits was evaluated under relatively aggressive conditions, i.e., $1 \mathrm{M} \mathrm{H}_{2} \mathrm{SO}_{4}$ at $23^{\circ} \mathrm{C}$ at an anodic current density $20 \mathrm{~mA} \mathrm{~cm}{ }^{-2}$, using electrochemical impedance spectroscopy. ${ }^{60}$ Typical findings are shown as a Nyquist plot in Fig. 9(d). It is clear that thinner deposits show clear evidence of porosity through to the steel in the form of a reduced charge transfer resistance, despite the use of a well formulated Watts nickel bath under closely controlled conditions. In the case of composite deposits, much lower porosity values for thin nickel-graphite layers have been experienced using a vertical rectangular channel flow ${ }^{34}$ or a commercial reel-to-reel coil plating line.

Our ability to disperse tribologically attractive but hydrophobic particles is evidenced by recent success with, e.g. electroplating of copper containing fluorinated graphite particles ${ }^{78}$ and deposition of tungsten disulphide
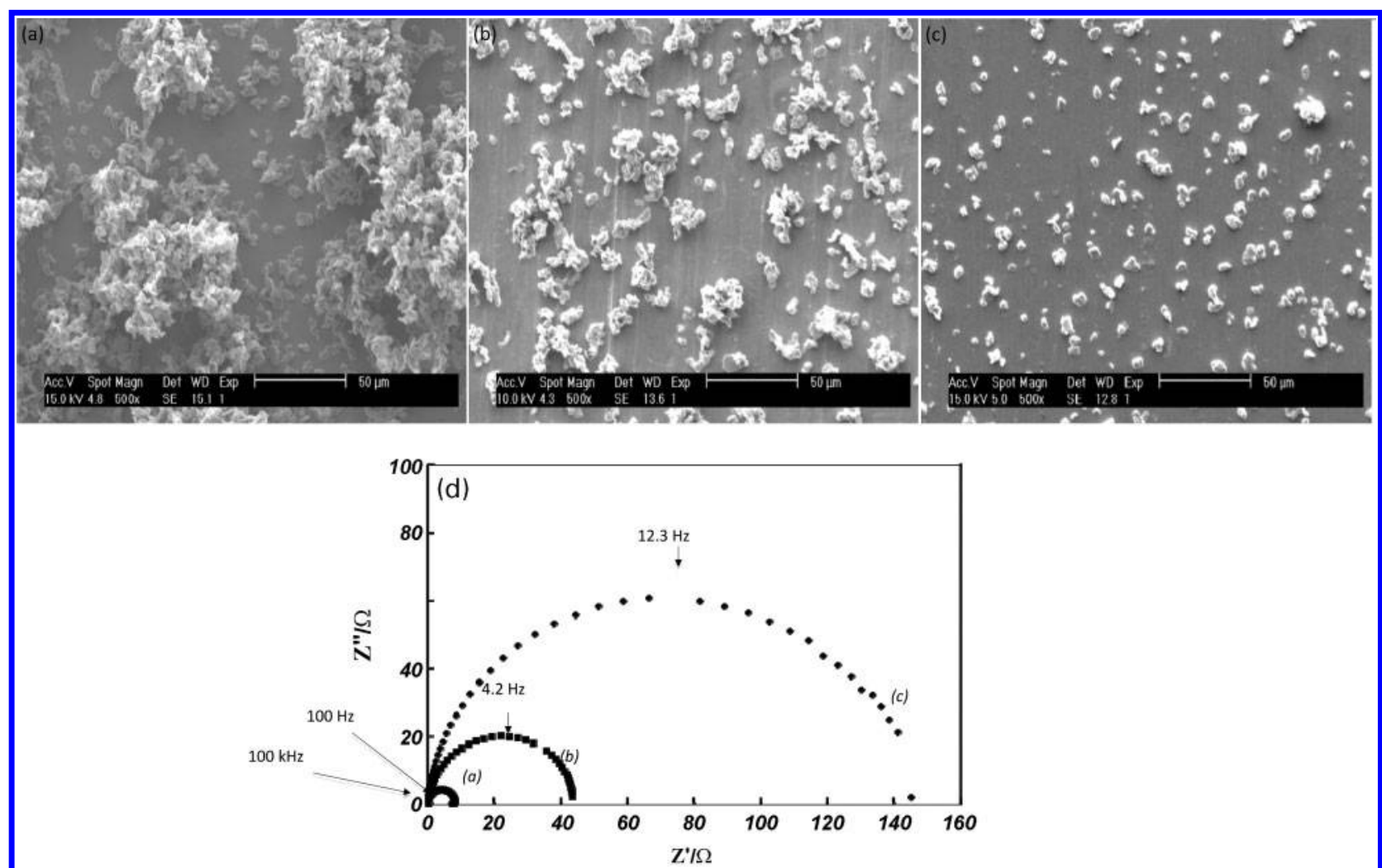

$a, b$ and $c$ SEM images of Ni/graphite composite deposits onto a mild steel plate from a Watts bath containing surfactant and $10 \mathrm{~g} \mathrm{dm}^{-3}$ graphite particles in a a Hull cell at a current density of $20 \mathrm{~mA} \mathrm{~cm}$; $b$ a magnetically stirred beaker cell, current density $20 \mathrm{~mA} \mathrm{~cm}{ }^{-2}$; $c$ a rectangular channel flow cell at a current density of $100 \mathrm{~mA} \mathrm{~cm}^{-2}$ and a mean upward linear flow rate of $23 \mathrm{~cm} \mathrm{~s}^{-1}$. In all cases, deposition charge was $3 \mathrm{mC} \mathrm{cm}^{-2}$ and the solution temperature was $333 \mathrm{~K} ; d$ EIS spectra of Ni-graphite deposits in $1 \mathrm{M} \mathrm{H}_{2} \mathrm{SO}_{4}$ at $23^{\circ} \mathrm{C}$, at the corrosion potential, showing the decreased corrosion resistance of thin nickel coatings: $1 \mu \mathrm{m}, 5 \mu \mathrm{m}$ and $5 \mu \mathrm{m}$ nickel coatings, which are better than the bare mild steel. After Justowiak-Brenska et al..$^{60}$

9 Ni-graphite composite coating for electrical conductivity. After Justowiak-Brenska et al. ${ }^{60}$ 


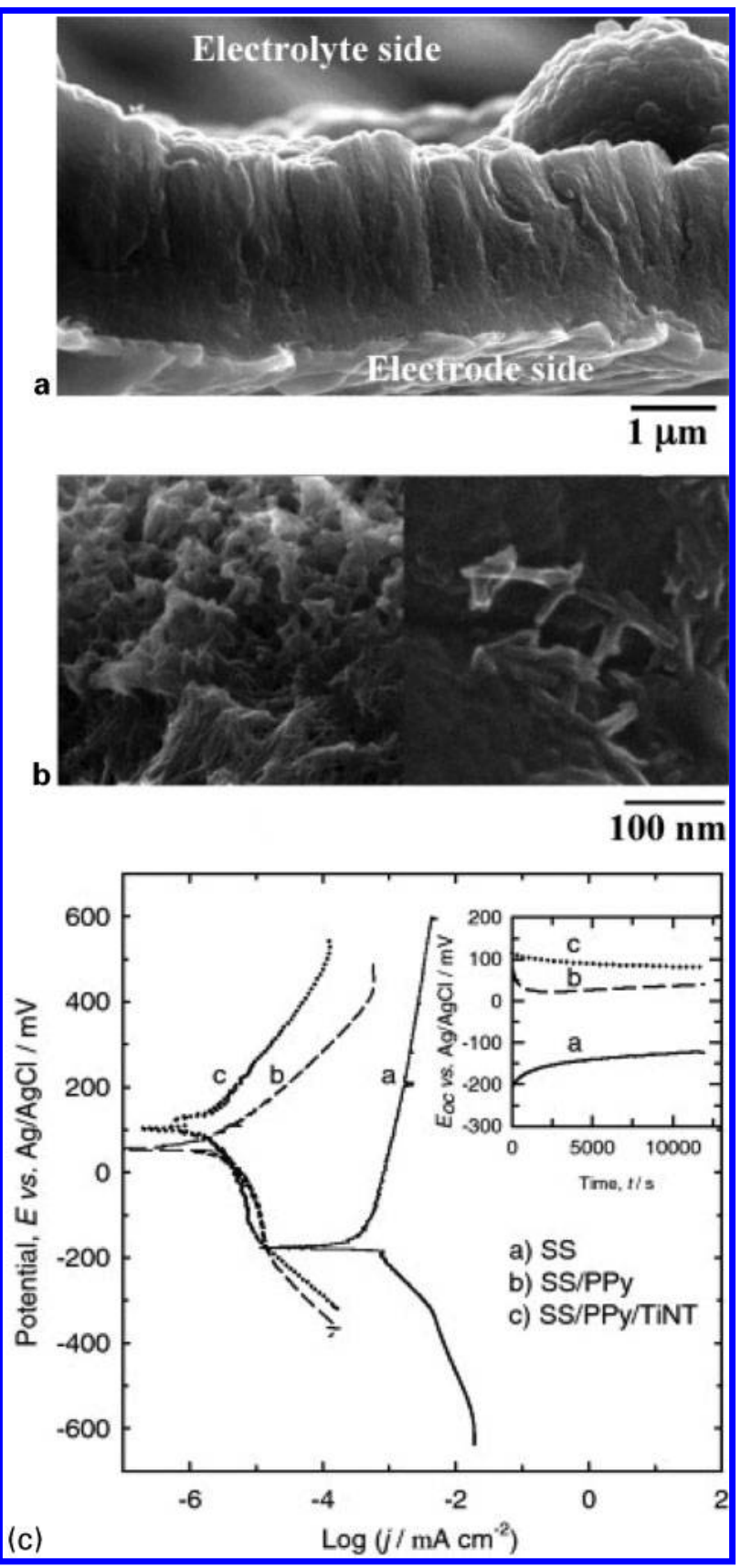

a Cross-sectional SEM image of the deposit, $b$ SEM image showing the morphology of the PPy/TiNT coating and $c$ linear polarisation behaviour of: a SS substrate (continuous line), SS/PPy (dashed line) and SS/ PPy/TiNT (dotted line) in $3 \% \mathrm{w} / \mathrm{v} \mathrm{NaCl}$ at $2 \mathrm{mV} \mathrm{s}^{-1}$ potential sweep rate. Inset: potential vs. time curves for the three samples in the same electrolyte. Temperature: $298 \mathrm{~K}$. After Herrasti et al. ${ }^{70}$

$10 \mathrm{PPy} / \mathrm{TiNT}$ coating anodically deposited on stainless steel (SS) from a magnetically stirred solution containing $0.1 \mathrm{~mol} \mathrm{dm}^{3}$ oxalic acid, $0.5 \mathrm{~mol} \mathrm{dm}^{3}$ pyrrole and $1 \mathrm{~g} \mathrm{dm}^{-3}$ of TiNT at $25^{\circ} \mathrm{C}$ by linear sweep voltammetry from $-0.3 \mathrm{~V}$ to $0.9 \mathrm{~V}$ vs. $\mathrm{Ag} / \mathrm{AgCl}$ at $50 \mathrm{mV} \mathrm{s}^{-1}$

particles in cobalt using an electroless bath with dimethyborane reducing agent. ${ }^{79}$ The former has been used as an improvement on carbon cathodes in alkaline batteries while the latter is attractive as a high performance surface under dry contact sliding conditions.

Zn-ceramic particle composite coatings have been increasingly considered as sacrificial coatings on steel for corrosion protection. For example, Tuaweri and Wilcox have studied $\mathrm{Zn}-\mathrm{SiO}_{2}$ coatings deposited from acid sulphate baths at $\mathrm{pH} 2 \cdot 0-2 \cdot 5 .{ }^{48}$ The variables studied included $\mathrm{pH}, \mathrm{SiO}_{2}$ loading in the bath $\left(13-52 \mathrm{~g} \mathrm{dm}^{-3}\right)$, current density (1-8 $\left.\mathrm{A} \mathrm{dm}^{-2}\right)$, degree of vibratory agitation and use of a bath addition agent. The particle content of the deposit peaked at ca. $3 \mathrm{~A} \mathrm{dm}^{-2}$. The deposits showed increased silica levels in outer regions (possibly due to increased local $\mathrm{pH}$ ) and was adversely affected (burned and darkened) by use of the addition agent This study of a complex but practical composite deposition serves to show some of the many variables affecting the particle loading and quality of composite deposits. The $\mathrm{Zn}-\mathrm{Ni}-\mathrm{SiO}_{2}$ system would prove a complex but challenging one to model.

Recently, the diversity of inclusions has widened and

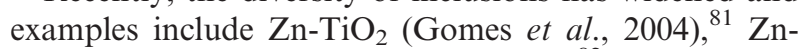
$\mathrm{Ni}-\mathrm{Al}_{2} \mathrm{O}_{3}$ (Tulio and colleagues, 2007); ${ }^{82} \mathrm{Zn}-\mathrm{Ni}-\mathrm{Al}_{2} \mathrm{O}_{3}$ (Sancakoglu et al., 2011), ${ }^{83} \mathrm{Zn}$-yttria stabilised zirconia, (Xia and co-workers, 2009), ${ }^{84} \mathrm{Zn}$-hybrid nanoparticles, (Kammona et al., 2009) ${ }^{85}$ and Zn-graphite (Muralidhara et al., 2012). ${ }^{86}$ It is now timely to see a comparative study of different (or mixed) ceramic particles in zinc and zinc alloy deposits.

\section{Complex, metal-hybrid particle and hierarchical coatings}

Recently, multiple particle types have been used in metal composites. One of the authors (FCW) has used Ni-SiCPTFE-graphite coatings for the six internal combustion cylinder surfaces of a 1987 Porsche 911 car, the strategy being to employ the carbide for wear resistance and improved toughness with the PTFE for self-lubrication and graphite for both improved lubrication and oil retention. The vehicle has covered over 35,000 miles with reduced oil use. ${ }^{76}$ Mixed conducting polymer films-inert particle composite electrodeposits have also been used for corrosion protection e.g. thin polypyrrole (PPy) films $(2 \mu \mathrm{m})$ containing titanate nanotubes (TiNT) were anodically deposited from $0.5 \mathrm{~mol} \mathrm{dm}^{-3}$ pyrrole (Py) and $1 \mathrm{~g} \mathrm{dm}^{-3}$ of TiNT in $0 \cdot 1 \mathrm{~mol} \mathrm{\textrm {dm } ^ { - 3 }}$ aqueous oxalic acid on $904 \mathrm{~L}$ stainless steel (SS) $0 \cdot 1 \mathrm{~mm}$ thickness at $298 \mathrm{~K}$ (Fig. 10). ${ }^{70}$ Electron microscopy showed that the nanotubes were adsorbed on the PPy surface and uniformly dispersed in a random orientation in the polymer matrix. The PPy/TiNT composite contained $<10$ wt. $\%$ titanates which showed an increase of 53\% in coating hardness compared to polypyrrole alone. The TiNT provided nucleation centres to catalyse the polymerisation of pyrrole and could adsorb up to $240 \mathrm{mg} \mathrm{g}^{-1}$ of the monomer. The corrosion rates for SS, SS/PPy and SS/PPy/TiTN composites, evaluated by linear sweep voltammetry and open-circuit potential measurements in $3 \% \mathrm{w} / \mathrm{v} \mathrm{NaCl}$, were $1 \cdot 61,0.008$ and $0.004 \mathrm{mg} \mathrm{dm}^{-2} \mathrm{day}^{-1}$, respectively, indicating that corrosion rates of stainless steel dramatically decreased, by up to three orders of magnitude, in the presence of the composite films.

The uses of such hybrid particle composite coatings include improved tribology and wear resistance, corrosion protection or speciality applications, utilising particular magnetic or electronic properties as discussed in a recent book. ${ }^{73}$

Particles may, themselves, be two-phase, as in the case of active internal contents which can release in service, 
e.g. a) liquid lubricants in microcapsules dispersed in a metal deposit, ${ }^{91,96}$ precious metal catalyst particles within titanate nanotubes ${ }^{71}$ or polyaniline within an anodised film. ${ }^{72}$

The majority of specialised composites continue to be used for engineering wear resistance and tribology in aerospace and automotive environments but emerging speciality composites also include:

1. CoNiMnP as permanent magnets, ${ }^{87}$

2. $\mathrm{Ni}-\mathrm{TiO}_{2}$ sintered $\mathrm{NdFeB}$ permanent magnets, ${ }^{88}$

3. $\mathrm{Ag} / \mathrm{TiO}_{2}$ for speciality electronic materials, ${ }^{89}$

4. Ni-graphite as battery electrodes and PEM fuel cell bipolar flow-field plates. ${ }^{34,60}$

5. precious metals in protonated titanate nanotubes as chemical catalysts, ${ }^{77}$ and

6. polyaniline in $\mathrm{TiO}_{2}$ nanotubes. ${ }^{72}$

The possibility of achieving hierarchical structures, such as 'tube-in tube' particles embedded in a metal matrix has recently been made possible by the achievement of electrophoretic deposition of titanate nanotubes into the pores of a nanotubular array produced by anodising of a titanium surface. ${ }^{69}$

This review has considered cathodic electroplating but anodising has been used as a complementary technique in special cases ${ }^{49,72}$ as has electroless plating. ${ }^{39-43} \mathrm{~A}$ forthcoming review in this journal will discuss nanostructured (including composite) coatings achieved by either plating or anodising. ${ }^{90}$

\section{Conclusions and future developments}

Several general conclusions can be made regarding composite plating:

1. Diversity. Traditionally, single metal matrices have tended to be co-deposited with spheroidal or irregularly shaped particles having a diameter of, perhaps $1-100 \mu \mathrm{m}$. The material, size and shape of inclusions continue to diversify as materials become more freely available and nanostructured particles can now include hybrid fibres and tubes while alloy metal plating or anodic films having controlled pore structure and more intelligent particles have become topical.

2. History. While there are examples of plated composite coatings dating back to the 1920s, early developments were most pronounced in the $1960 \mathrm{~s}$ and 70 s in Europe.

3. Traditional composite coatings showed a focus on $\mathrm{Ni}-\mathrm{SiC}, \mathrm{Cu}-\mathrm{Al}_{2} \mathrm{O}_{3}$, Ni-PTFE and $\mathrm{Cu}$-polystyrene; more recent diversification has included speciality markets in electronics and materials sectors of industry.

4. Mechanisms. While particle transport is well understood, the co-deposition of particles and their interaction with the depositing matrix metal remain poorly considered.

5. Models. The development of models describing plated composite coatings under controlled conditions in known bath compositions has been semicontinuous in the period 1972-2002; more practical, versatile and user-friendly ones which use multiphysics approaches and are not so dependent on specific, experimentally derived and empirical factors are needed.

6. Uses. Traditional uses for wear resistance and improved lubrication in automotive and aerospace have been accompanied by electronic, optical and magnetic materials for speciality ones.

7. Evaluation of the coatings. Optical and scanning electron microscopy, SEM of surface are commonplace; cross-sectional imaging and transmission electron microscopy, TEM with selected area electron diffraction (SAED) is rare but often necessary to provide sufficient resolution of features and local phase composition. The use of dc polarisation curves and EIS corrosion testing has become common, while these are rarely complemented with more practical corrosion exposure trials. Many applications involve wear situations such that tribological evaluation of coatings in controlled environments has become more important. Its long history means that the field of composite plating to include particles into a metal matrix coating is well established and semi-continuous developments have led to considerable diversity in materials, structure and applications.

Continued advances in our fundamental knowledge and the practice of composite plating for increasingly demanding service environments require a number of interactive research directions to develop next generation composite coatings, including the following:

1. Baths. Detailed dispersion studies are needed including particle analysis (particle size distribution and shape), electrophoresis (particle zeta potential, charge and velocity) and stability of the bath dispersion (sedimentation rate, tendency to agglomeration, etc). The importance of single and mixed surfactants (including ageing effects and the rate of consumption at each electrode) needs to be established.

2. Deposits. The importance of electrode geometry on the quality of the deposit needs quantifying, in the light of major differences in the literature, including those between fundamental studies and practical developments. It is also important to clarify the relationship between particle dispersions in the bath and those in the resultant deposit. In-situ absorption spectroscopy (e.g. Raman and infrared) studies would provide much more detail on species adsorbed on both the particles and on the growing deposit. It is also important to explore more alloy deposits as suitable matrices and to clarify the circumstances where particle shape and size (including nanostructured vs. micron sized) dispersions offer clear benefits to the engineering properties of the composite deposits.

3. Process mechanism, modelling and simulation. It is now important to bridge the gap between fundamental modelling studies which consider idealised baths and practical electrode geometries and plating conditions to those encountered in surface finishing practice. The use of standard software packages (particularly those based on multi-physics approaches which consider bath composition, plating conditions, electrode geometry and bath agitation to predict the degree of particle inclusion) would considerably generalise models and their usefulness by non-experts. Models should consider the reductions in electrolyte conductivity and solution viscosity arising from the high concentration of suspended particles.

4. Experimental techniques for coating characterisation. EIS of corroding samples should be complemented 
by long-term studies of corrosion and porosity under controlled flow. SEM imaging should be complemented and extended by the use of cross-sectional SEM imaging of the coating-substrate interface and particle-matrix interface while TEM imaging coupled to SAED would facilitate phase compositional information on the particles and the metal matrix. Microhardness data could be reinforced by the use of atomic force microscopy (AFM) to probe particle-surface interactions. A wider variety of tribological tests should be applied to coatings, including dry, wet and multi-phase, e.g. slurry environments with impacting, rotating, sliding and scratched contact. It is important to improve our knowledge of the chemistry of composite surfaces by the wider use of surface science and spectroscopy tools to improve wear mechanisms of composites. In view of the movement towards nanometre sized inclusions, it is important to establish the true advantages of such materials compared to traditional ones used in composite deposits.

5. Practical operations. A wide range of composite coatings has been studied but it is not always clear which should be chosen for a particular application. Therefore, comparative studies on composite deposits are essential in creating a 'design selector'. As many plating baths must economically survive many years of use, housekeeping and ageing effects, together with their remediation, are important. Environmental issues, such as bath reclamation, waste treatment and the fate of environmentally persistent surfactants, must be considered.

In a futuristic look ahead, we might imagine the significant contribution of next generation composite coatings to smart coatings capable of diagnostic or timedependent and responsive (e.g. tribological) interactions between particle and metal matrix and between the surface and changes in its service environment, e.g, load direction and magnitude, the nature of the counter body and the type of contact (e.g. sliding or impacting, intermittent or continuous) together with the nature of the environment (e.g, temperature, humidity and degree of corrosivity) for the composite deposit. An example might be 'self-healing' coatings which helped remediate corrosion or wear damage by local materials chemistry. It would also be possible to incorporate antibacterial, antifungal, aromatic or electronic sensor particles into plated (or anodised) layers.

\section{Acknowledgements}

The authors are grateful to the Editors, Mr Clive Larson and Dr Geoff Wilcox for their knowledge of composite plated coatings together with their encouragement to prepare this review. FCW acknowledges the expertise shown and guidance provided during his early training in composite plating under the leadership of Ir Kees Helle and the colleagueship of Andrei Kamp and Tini van den Heuvel in AKZO's Arnhem research laboratories in 1974.

\section{References}

1. C. T. J. Low, R. G. A. Wills and F. C. Walsh: Surf. Coat. Technol., 2006, 201, 371-383.

2. P. A. W. Lansdell and J. P. G. Farr: Trans. IMF., 2004, 90, 105113.
3. C. G. Fink and J. D. Prince: Trans. Amer. Electrochem. Soc., 1928, 54, 315-320.

4. J. R. Roos, J-P. Celis, J. Fransaer and C. Buelens: J. Minerals Metals Soc., 1990, 42, 60-63.

5. K. Helle and F. C. Walsh: Trans. IMF, 1997, 75, 53-58.

6. M. Musiani: Electrochim. Acta, 2000, 45, 3397-3402.

7. C. Kerr, B. D. Barker, F. C. Walsh and J. Archer: Trans. IMF., 2000, 78, 171-178

8. N. Feldstein: 'Composite Electroless Plating', Ch. 11 in Electroless Plating. Fundamentals and Applications, G.O. Mallory and J.B. Hajdu (Eds.), AESF, 1990, pp. 269-287.

9. A. Hovestad and L. J. J. Jannsen: Electrodeposition of Metal Matrix Composites by Co-deposition of Suspended Particles, in Modern Aspects of Electrochemistry No 38, B.E. Conway (Ed.), 2005, 475-486.

10. A. Hovestad and L. J. J. Jannsen: J. Appl. Electrochem., 1995, 25, 519-527.

11. J-P. Celis, J. R. Roos and C. Buelens: J. Electrochem. Soc., 1987, 134, 1402-1408.

12. P. L. Cavallotti, M. Bestetti, S. Franz and A. Vicenzo: Pure Appl. Chem., 2011, 83, 281-294.

13. P. J. F. Harris: 'Carbon Nanotube Science: Synthesis, Properties and Applications', Cambridge University Press, 2011; ISBN 9780521535854

14. H. Friedman, O. Eidelman, Y. Feldman, A. Moshkovich, V. Perfiliev, L. Rapoport, H. Cohen, A. Yoffe and R. Tenne: Nanotechnology, 2007, 18, 11573-115711.

15. C. T. J Low, F. C. Walsh, M. H. Chakrabarti, M. A. Hashim and M. A. Hussain: Carbon, 2013, 54, 1-21.

16. D. V. Bavykin and F. C. Walsh: 'Titanate and Titania Nanotubes: Synthesis, Properties and Applications', Royal Society of Chemistry Nanoscience and Nanotechnology Monograph, 2009; ISBN 978-1-84755-910-4.

17. R. V. Williams and P. W. Martin: Trans. IMF., 1964, 42, 182-187.

18. R. Bazzard and P. J. Boden: Trans. IMF., 1972, 50, 63-69; $207-$ 210.

19. E. A. Brandes and D. Goldthorpe: Metallurgia, 1967, 76, 195-198.

20. N. Guglielmi: J. Electrochem. Soc., 1972, 119, 1009-1012.

21. M. Degrez and R. Winand: Electrochim. Acta. 1984, 29, 365-371.

22. J-P. Celis, J. R. Roos and C. Buelens: J. Electrochem. Soc., 1987, 134, 1402-1408.

23. A. Hovestad: 'Electrochemical Deposition of Metal Matrix Composites', PhD thesis, University of Eindhoven, 1997.

24. R. Morana: 'The Influence of Particle Type and Process Conditions on Electrodeposited Composites', PhD Thesis, University of Loughborough, 2006.

25. J. L. Valdes: J. Electrochem. Soc., 1987, 133, 223C-228C.

26. B. J. Hwang and C. S. Hwang: J. Electrochem. Soc., 1986, 133, 259-264; B.J. Hwang and C.S. Hwang: J. Electrochem. Soc. 1993, 140, 979-984.

27. J. Fransaer, J. P. Celis and J. R. Ross: J. Electrochem. Soc. 1992, 139, 413-418.

28. G. Maurin and A. Lavanant: J. Appl. Electrochem, 1995, 25, 1113 1121.

29. P. M. Vereecken, I. Shao and P. C. Searson: J. Electrochem. Soc. 2002, 147, 2572-2575.

30. P. Bercot, E. Pena-Munoz and J. Pagetti: Surf. Coat. Technol., 2002, 157, 282-289.

31. F. Wang, S. Arai and M. Endo: Mater. Trans., 2004, 45, 13111316.

32. P. Bercot and J. Takadoum: Chapter 9. Electrodeposition. In J. Takadoum (Ed), 'Nanomaterials \& Surface Engineering', Wiley. London, 2010

33. D. Koleva, N. Boshkov, D. Raichevski and L. Veleva: Trans. IMF., 2005, 83, 188-193.

34. J. Lapinski, D. Pletcher and F. C. Walsh: Surf. Coat. Technol., 2011, 205, 5205-5209.

35. N. S. Qu and F. Xiao: Trans. IMF., 2013, 91, 89-95.

36. E. Rudnik: Trans. IMF, 2009, 87, 239-245.

37. E. Rudnik, L. Burzynska and M. Gebka: Trans. IMF, 2011, 89, 3338.

38. G. M. Xu and J. Z. Cui: Trans. IMF, 2004, 82, 129-131.

39. M. Petrova, Z. Noncheva and E. Dobreva: Trans. IMF, 2011, 89, 89-94.

40. K.N. Srinivasan and P. Thangavelu, 'Electroless Deposition of Ni$\mathrm{P}$ Composite Coatings containg Kaolin Particles', Trans. IMF, 2012, 90, 105-112.

41. M. Petrova, E. Dobreva and Z. Noncheva: Trans. IMF, 2006, 84, 99-104. 
42. M. Georgieva, N. Razkazov, M. Petrova, G. Ardeev and D. Dobrev: Trans. IMF, 2013, 91, 96-100.

43. S. Mirzamohammadi, R. Kiarasi, M. K. Aliov, A. R. Sabur and A. Hassanzadeh-Tabrizi: Trans. IMF, 2011, 89, 93-99.

44. M. Mulukutla, A. Singh and S. P. Harimkar: Trans. IMF, 2012, 90, 316-323.

45. M. Petrova: Trans. IMF, 2004, 82, 43-50.

46. H. C. Barshilia, M. S. Prakash, A.Poojari and K. S. Rajam: Trans. IMF, 2004, 82, 4-8.

47. F. Hu and K. C. Chan: Trans. IMF, 2006, 84, 252-255.

48. T. J. Tuaweri and G. D. Wilcox: Trans. IMF, 2007, 85, 245-253

49. O. Zubillaga, E. J. Cano, I. Azkarate, G. Imbuluzqueta and M. Insausti: Trans. IMF, 2009, 89, 315-319.

50. S. Surviliene, A. Cesuniene and R. Juskenas: Trans. IMF, 2004, 82 , 185-189.

51. S Surviliene, A. Cesuniene, V. Jasulaitiene and D. Businskiene: Trans. IMF, 2008, 86, 309-314.

52. N. S. Qu, K. C. Chan and D. Zhu: Trans. IMF., 2003, 90, 103-105.

53. C. T. Low, J. O. Bello and F. C. Walsh: 'The influence of surfactants on the tribological properties of an electrodeposited $\mathrm{Ni}$ nanoparticulate SiC coating', Trans. IMF., 2014, to be submitted.

54. B. Gyftou, M. Stroumbouli, E. A. Pavlatou and N. Spyrellis: Trans. IMF, 2002, 80, 88-91.

55. D. R. Gabe, F. C. Walsh, G. D. Wilcox and J. Gonzalez-Garcia: J. Appl. Electrochem., 1998, 28, 759-780.

56. C. T. Low, C. Ponce-de-León and F. C. Walsh: Australian J. Chem., 2005, 58, 246-262.

57. S. J. Osborne, W. S. Sweet, K. S. Vecchio and J. B. Talbot: $J$ Electrochem. Soc., 2007, 154, D394-D399.

58. S. J. Osborne, W. S. Sweet, K. S. Vecchio and J. B. Talbot: J. Electrochem. Soc., 2007, 154, D394-D399.

59. D. Thiemig, J. B. Talbot and A. Bund: J. Electrochem. Soc., 2007, 154, D510-D515.

60. A. Justowiak-Brenska, J. Lapinski, D. Pletcher and F. C. Walsh: Trans. IMF, 2012, 90, 156-160.

61. C. T. J. Low, E. P. L. Roberts and F. C. Walsh: Electrochim. Acta, 2007, 52, 3831-3840.

62. C. T. J. Low and F. C. Walsh: Trans. IMF, 2008, 86, 315-325.

63. F. C. Walsh and K. Helle: AKZO CRT Laboratories, 1973, unpublished work

64. J. Fransaer and J.P.Celis: 'Investigation of the Codeposition of Polymer Lattices with Copper on a Rotating Disk Electrode'. Materials Research Society Proceedings, 1996, pp. 451-475.

65. Gyawali, S. H. Cho, D. J. Woo and S. W. Lee: Trans. IMF, 2012, 90, 274-280.

66. L. Burzynska, E. Rudnik, L. Blaz, M. Kotula, Z. Sierpinski and W. E. Szymanski: Trans. IMF, 2003, 81, 193-198.

67. H. B. Muralidhara, Y. A. Nayake, J. Balasubramanyam, K. Y. Kumar, H. Hanumanthappa and M. S. Veena: J. Chem. Pharm. Res., 2012, 4, 440-449.

68. C. T. J. Low, J. O. Bello, J. A. Wharton, R. J. K. Wood, K. R. Stokes and F. C. Walsh: Surf. Coat. Technol., 2010, 205, 18561863.

69. D. V. Bavykin, L. Passoni and F. C. Walsh: 'Hierarchical Tube-intube Structures Prepared by Electrophoretic Deposition of Titanate Nanotubes into a $\mathrm{TiO}_{2}$ Nanotubular Array', Chem. Comms., 2013, submitted.

70. P. Herrasti, A. N. Kulak, D. V. Bavykin, C. Ponce de León, J. Zekonyte and F. C. Walsh: Electrochim. Acta, 2011, 56, 1323-1328.
71. F. C. Walsh, D. V. Bavykin, L. Torrente-Murciano, A. A. Lapkin and B. A. Cressey: Trans. IMF, 2006, 84, 293-299.

72. A. Jagminas, A. Balciunaite, G. Niaura and L. TamasauskaiteTamasiunaite: Trans. IMF, 2012, 90, 311-315.

73. C. T. J. Low and F. C. Walsh: 'Multifunctional Nanostructured Metallic Coatings by Electrodeposition', Chapter 10 in R.J.K. Wood, (Ed), 'Multifunctional Materials for Tribological Applications', Pan Stanford, 2013.

74. K. Helle: 'Electroplating with Inclusions', Proc. 4th Int. Conf. in Organic Coatings, Science and Technology, 2, 1978, Athens, p. 264.

75. K. Helle and R. C. Groot: US Patent 4302374, 1981; B. Cooray, P. Hope, J. Vleggaar, K. Helle and A. Roos: US Patent 4795660, (assigned to AKZO NV), 1989.

76. F. C. Walsh: unpublished work, 2006.

77. F. C. Walsh, D. V. Bavykin, L. Torrente-Murciano, A. A. Lapkin and B. A. Cressey: Trans. IMF., 2006, 84, 293-299.

78. E. Plumier, F. Chassaine, G. Terwagne, J. Delhalle and Z. Mekhalit: Appl. Surf. Sci., 2011, 212, 271-278.

79. H. Friedman, O. Eidelman, Y. Feldman, A. Moshkovich, V. Perfiliev, L. Rapoport, H. Cohen, A. Yoffe and R. Tenne: Nanotechnology, 2007, 18, 115703-115707.

80. J. Lee and J. B. Talbot: J. Electrochem. Soc., 2005, 152, C706 C715.

81. A. Gomes, S. M. I. Pereira, M. H. Medonca and F. M. Costa: 'Composite Films prepared by Pulsed Electrodeposition', J. Solid State Electrochem., 2004, 9, 190-196.

82. P. C. Tulio, S. E. B. Rodrigues and I. Carlos: Surf. Coat. Technol., 2007, 209, 5921-5930.

83. O. Sancakoglu, O. Culha, M. Toparli, B. Agady and E. Celik: Mater. Design, 2011, 32, 4045-4061.

84. X. Xia, I. Zhitomitsky and J. R. McDermid, J. Mats. Process.: 2009, 209, 2632-2640.

85. O. Kammona, K. Kotti, C. Kiparissides, J. P. Celis and J. Fransaer: Electrochim. Acta, 2009, 54, 2450-2457.

86. H. B. Muralidhara, Y. Arthoba Nayaka, J. Balasubramanyam, K. Y. Kumar, H. Hanumanthappa and M. S. Veena: J. Chem. Pharm. Res., 2012, 12, 440-449.

87. N. S. Qu, F. Jiao: Trans. IMF., 2012, 90, 92-97.

88. Q. Li, N. Gao, J. P. Wang and B. Chen: Trans. IMF, 2009, 87, 149154.

89. A. M. Centaragiu, P. Cojocaru, G. Carac, C. Gheorghies and L. Magagnin: Trans. IMF, 2011, 89, 39-43.

90. C. T. J. Low, C. Ponce de Leon and F. C. Walsh: 'The Deposition of Nanostructured Materials by Electroplating and Anodising: a Diverse and Powerful Range of Emerging Surface Coatings', Trans. IMF, 2014, to be submitted.

91. A. Sohrabi, A. Dolati, M. Ghorbani, A. Monfared and P. Stroeve: Mater. Chem. Phys., 2010, 121, 497-505.

92. J. Fransaer and J. P. Celis: Galvanotechnik, 2001, 92, 1544-1555.

93. J. Fransaer, J. B. Talbot and J. L. Stojak: 'Review of Electrocodeposition', Adv. Electrochem. Sci. Eng., vol. 7, 2001, pp. 193-221, Eds. R.C. Alkire and D.M. Kolb, Wiley-VCH Verlag GmbH.

94. A. Gajewska, B. Szeptycka and A. Nakonieczny: Trans. IMF, 2009, 87, 141-148

95. H. Liu, R. X. Guo, F. Viejo, G. E. Thompson and Z. Liu: Trans. IMF, 2013, 91, 101-112.

96. A. Malfliet, G. Deferme, L. Stappers and J. Fransaer: J. Electrochem. Soc., 2007, 154, D50-D56. 